\title{
NUEVOS PAISAJES Y NUEVAS FORMAS DE PRODUCCIÓN: LA EXPANSIÓN DE LAS EMPRESAS DE SERVICIOS Y DE LOS ASALARIADOS EN LOS ESPACIOS VITÍCOLAS DEL DUERO
}

\author{
Fernando Molinero Hernando \\ Universidad de Valladolid \\ molinero@fyl.uva.es \\ ORCID iD: https://orcid.org/0000-0003-4055-0341 \\ Marta Martínez Arnáiz \\ Universidad de Burgos \\ mmar@ubu.es \\ ORCID iD: https://orcid.org/0000-0002-5894-4288
}

Recibido: 17/01/2020; Aceptado: 22/07/2020

Cómo citar este artículo / citation: Molinero Hernando, Fernando y Martínez Arnáiz, Marta (2020). Nuevos paisajes y nuevas formas de producción: la expansión de las empresas de servicios y de los asalariados en los espacios vitícolas del Duero. Estudios Geográficos, 81 (289), e044. https://doi.org/10.3989/estgeogr.202058.058

RESUMEN: El valle del Duero en España conoce un vigoroso proceso de expansión vitícola y vinícola sin precedentes. Sus vinos, cada vez más valorados en el mercado nacional e internacional, se suman a los del Duero portugués. Juntos configuran un espacio vitivinícola de grandes viñedos y vinos, de extraordinario dinamismo y valor. El Douro viñateiro ha expandido su reconocimiento y valoración desde la desembocadura en Oporto hasta su nacimiento en Soria y el conjunto del valle, con sus terrazas y campiñas próximas, ha adquirido fama vitícola mundial, merced a unos vinos cada vez más cotizados y a unos viñedos cada vez más cuidados y con inversiones procedentes de toda Europa y de América.

En este contexto, la viticultura tradicional está cambiando radicalmente; los antiguos pagos de viñedo, fraccionados en numerosísimas parcelas, se reorganizan en explotaciones vitícolas de dimensiones medias. Se ha producido una expansión espectacular del viñedo, principalmente en Rueda y la Tierra de Medina del Campo, así como en La Ribera del Duero y Toro. En este nuevo modelo de viticultura, muchos viticultores hacen más de gestores que de trabajadores de sus viñas. Es el modelo de viticultura del siglo XXI, que ha generado un paisaje nuevo, con bodegas de diseño que se rodean de ejércitos de viñas, perfectamente alineadas, formando pagos vitícolas de grandes extensiones para cuyo laboreo se recurre a la externalización laboral, con trabajadores en gran medida inmigrantes, organizados en empresas de servicios a la viticultura. Todo ello existe merced a la capacidad de empleo de la viticultura moderna, que ha logrado cambiar el rumbo regresivo de las áreas rurales en el valle del Duero.

PALABRAS CLAVE: Externalización laboral agraria, empresas de servicios vitícolas, trabajo inmigrante, asalariados, viticultura moderna, nuevos paisajes vitícolas.

\section{NEW LANDSCAPES AND NEW FORMS OF PRODUCTION: THE EXPANSION OF SERVICES COMPANIES AND EMPLOYEES IN THE DOURO WINE-GROWING AREAS}

ABSTRACT: The Douro Valley in Spain is undergoing a vigorous process of viticultural and winemaking expansion without precedents. Its wines, increasingly valued in the national and international market, are added, in prestige, to the Portuguese Douro wines. Together, they make up a wine-growing area of great vineyards and wines, of extraordinary dynamism and value. The Douro viñateiro has expanded its recognition and appreciation from its mouth in Porto to its source in Soria. The whole valley has acquired world-wide fame for its wines, which are becoming more and more prized, and also for its increasingly well-care vineyards, with investments from all over Europe and America.

In this context, traditional viticulture is changing radically; the old vineyards fields, divided into very numerous plots, are reorganized into medium-sized wine-growing holdings, There has been a spectacular expansion of the vineyard, mainly in Rueda and the Tierra de Medina del Campo, as well as in some areas of La Ribera del Duero and Toro. In this new model of viticulture, many winegrowers are more like managers than workers in their vineyards. It is the model of viticulture in 21st century, which has generated a new landscape, with design wineries surrounded by vineyards, perfectly aligned, forming large wine-growing plots. For its tillage, the work is outsourced, with workers, mostly immigrants, organized in viticulture service companies. All this happens thanks to the employment capacity of modern viticulture, which has been able to change the regressive course of rural areas in the Douro Valley.

KEY WORDS: agricultural labour outsourcing, viticulture services companies, immigrant workers, agricultural salaried employees, modern viticulture, new viticulture landscapes.

Copyright: @ 2020 CSIC. Este es un artículo de acceso abierto distribuido bajo los términos de la licencia de uso y distribución Creative Commons Reconocimiento 4.0 Internacional (CC BY 4.0). 


\section{INTRODUCCIÓN: LA FUERTE EXPANSIÓN DE LA NUEVA VITICULTURA EN EL DUERO}

El espacio vitícola del Duero se extiende por una franja de tierras del lecho mayor del río y de sus terrazas, plataformas de areniscas y algunas campiñas de su margen meridional, además de las cuestas de los páramos y los bordes que delimitan el valle. Esta larga franja, incluidas algunas campiñas que desbordan por el sur, constituye hoy el territorio vitícola más dinámico de Europa, no sólo por la fuerte expansión de su viñedo, sino especialmente por el auge y consolidación de sus bodegas y vinos, lo que ha generado un dinamismo económico y social sin precedentes.

Para entender esta situación, es preciso encuadrarla en su contexto histórico. La vid, cultivo permanente, fue siempre exigente en mano de obra por las muchas labores requeridas a lo largo del año, tareas que culminaban con la vendimia -en el campo- y con la cría del vino -en la bodega-. El viñedo era un cultivo clave en la pequeña explotación familiar de subsistencia, dada su capacidad de empleo, que iba más allá del interés económico del vino para el autoconsumo y para la venta del excedente, pues la producción vitivinícola tenía un destacado valor estratégico en la diversificación de los riesgos de producción, en la ocupación casi continua de los miembros de la familia sin interferir en el tiempo con las labores de otros cultivos y en la reducción de la inseguridad económica (Huetz de Lemps, 1967; Molinero, 1979; Peña, 1987). Este último autor, en su trabajo sobre Tierra de Campos, calificaba el viñedo como "un cultivo de mano de obra" por los cuidados necesarios, muchos de ellos realizados en invierno, cuando no había otras ocupaciones (Peña, 1987, pp. 119-120). Por tanto, el viñedo, complementario del trigo y de otros cultivos de subsistencia, contribuía a ocupar a toda la familia en los periodos de mínima actividad, con fuertes exigencias puntuales de trabajo durante la vendimia, labor que requería todos los brazos familiares, incluidos los infantiles, a los que se sumaban incluso los de trabajadores asalariados temporeros.

Poco tiene que ver ese contexto productivo y laboral del viñedo tradicional con el actual de los vinos de calidad y de su plena integración en los circuitos comerciales. Poco, salvo que la vid sigue siendo un cultivo muy intensivo en trabajo $y$, aunque modernizado y mecanizado, mantiene bastantes tareas manuales que, si bien mecanizables, no están mecanizadas, en aras de la calidad. La expansión tradicional del cultivo sobre los territorios del Duero y su cambio de rumbo hacia la ex- celencia se producen en coincidencia con el fenómeno de la despoblación y la progresiva contracción del mercado laboral rural. La falta de brazos para las tareas que, además, se realizan con una cierta concentración temporal, ha generado nuevas formas de organización del trabajo, basadas en la externalización de las labores, a cargo de personal asalariado a demanda, gestionado por empresas de servicios. Estas surgen como un modo de adaptación y ajuste a las nuevas necesidades, al igual que ha ocurrido en regiones donde la agricultura a tiempo parcial tiene mucha entidad, como el Levante español y el Mediterráneo en general, donde la externalización de los trabajos solventa el problema de la falta de escala y se presenta como un freno al ajuste estructural clásico de concentración y aumento del tamaño de las explotaciones (Langreo, 2002; Arnalte, 2003; Saborá, 2006; Gallego, 2010). Ello permite aprovechar las economías de escala en un escenario compartido de necesidades y demandas, reducir costes de producción, aplicar innovaciones tecnológicas y disponer de mano de obra especializada.

Esta nueva y expansiva viticultura se basa en una mano de obra abundante y barata, a menudo aportada por inmigrantes, habitualmente organizados en empresas de servicios agrarios, con un abultado número de obreros, que mantienen el carácter "social" del cultivo de la vid y que hacen de los pueblos vitícolas territorios rurales dinámicos, progresivos, en crecimiento económico y con un fuerte empuje social, como analizamos en el caso del Duero español. Al hablar de "nueva viticultura" nos referimos a la que domina en la actualidad en el valle, en las terrazas y en las campiñas del tramo español del Duero, a lo largo de una franja de aproximadamente $250 \mathrm{~km}$ de largo por entre 10, y a veces 30 , y hasta $50 \mathrm{~km}$ de ancho en el sector más dilatado del valle. Se trata de tierras históricamente dedicadas al cultivo de la vid, cuya extensión superaba ampliamente la actual, que no alcanza las 50000 ha. La crisis de la filoxera de principios del siglo $\mathrm{XX},{ }^{1}$ la más fuerte de los años 1960 a 1980,y la escasez de mano de obra derivada del éxodo rural, redujeron sustancialmente los viñedos del Duero. Sin embargo, la sorprendente recuperación posterior ha dado lugar a una expansión firme y creciente. Esa fuerza expansiva no afecta por igual a todo el territorio duriense, pero, como conjunto, es un ámbito vitícola con cambios espectaculares, en donde convive la explotación tradicional, de corte familiar, con la nueva viticultura empresarial, que ha saltado a un mercado nacional e internacional en auge.

Ha sido este ambiente expansivo el que ha atraído capitales de fuera de la región y de fuera de España, 
que han construido modernas y grandes bodegas, que contrastan con las tradicionales: Codorniú y el Grupo Faustino, García Carrión y Solís, Ramón Bilbao, Domecq, Lurton, Louis Vuitton, Novartis..., son algunos ejemplos de inversores. A la expansión de viñedos y bodegas, por otro lado, le ha seguido el asentamiento de un gran número de inmigrantes, quienes han aportado una porción fundamental del trabajo necesario. Se ha de destacar que una hectárea de viñedo exige casi 60 veces más trabajo que una de cereal de secano (28 jornadas/año frente a 0,5). De ahí las claras oportunidades de empleo. No obstante, la mecanización de muchas labores, especialmente de la vendimia, reduce la cantidad de trabajo, pero sólo en los viñedos de vino blanco (DOP Rueda), donde prácticamente se recoge todo a máquina, frente a los de vino tinto -La Ribera y Toro- o rosado -Cigales-, donde la vendimia manual afecta a las tres cuartas partes de la superficie.
En la Tabla 1 se recogen los datos básicos de estos viñedos y comarcas. Abundan los empleos agrarios, que superan claramente al de agricultores perceptores de pagos PAC. Este hecho está relacionado con la importancia y magnitud de la mano de obra inmigrante empleada en las tareas agrícolas, y especialmente vitícolas, sobre todo en Rueda y la Ribera del Duero, y secundariamente en Toro y Cigales, por más que en estas últimas denominaciones se haya perdido una extensa superficie vitícola por causa de su modernización y reorganización (véase Mapa 1).

Un somero análisis de los datos de la Tabla 1 permite comprobar la tendencia creciente del viñedo en el valle del Duero y sus campiñas adyacentes, aunque en el mapa (Figura 1) aparece todavía con escasa entidad. Desde 1985 -cuando se había consumado el éxodo rural y se había casi llegado al máximo nivel de abandono de este cultivo- hasta 2017, aumenta en un $50 \%$ la superficie vitícola y, aunque no haya datos oficiales

TABLA 1

DATOS BÁSICOS DE LOS VIÑEDOS Y VITICULTORES DEL DUERO

\begin{tabular}{|c|c|c|c|c|c|c|c|c|}
\hline \multicolumn{9}{|c|}{ V I N E D O } \\
\hline Nombre DO & $\begin{array}{c}\text { № de } \\
\text { municipios }\end{array}$ & $\begin{array}{l}\text { Viñedo } \\
1985 \text { (ha) }\end{array}$ & $\begin{array}{l}\text { Viñedo } \\
2007 \text { (ha) }\end{array}$ & $\begin{array}{l}\text { Viñedo } \\
2017 \text { (ha) }\end{array}$ & $\begin{array}{l}\text { Superficie } \\
\text { municipal } \\
\text { total (ha) }\end{array}$ & $\begin{array}{l}\text { \% viñedo/ } \\
\text { total (2017) }\end{array}$ & $\begin{array}{l}\text { Ha inscritas } \\
2017 / 18\end{array}$ & $\begin{array}{c}\text { Viticultores } \\
\text { inscritos } \\
2017 / 18\end{array}$ \\
\hline Rueda & 66 & 7.368 & 10.329 & 16.549 & 289.398 & 5,72 & 16.165 & 1.540 \\
\hline Ribera del Duero & 82 & 12.056 & 20.612 & 22.783 & 324.910 & 7,01 & 21.633 & 8.052 \\
\hline Toro & 14 & 5.657 & 7.177 & 6.604 & 75.150 & 8,79 & 5.626 & 1.026 \\
\hline Cigales & 11 & 2.489 & 3.437 & 2.497 & 55.720 & 4,48 & 1.963 & 388 \\
\hline Arribes & 33 & 5.773 & 3.308 & 3.146 & 170.828 & 1,84 & 245 & 207 \\
\hline Tierra del Vino & 54 & 3.083 & 2.101 & 1.634 & 172.193 & 0,95 & 639 & 177 \\
\hline Total general & 260 & 36.426 & 46.964 & 53.213 & 1.088 .199 & 4,89 & 46.271 & 11.390 \\
\hline \multicolumn{9}{|c|}{ OTROS } \\
\hline Nombre DO & $\begin{array}{l}\text { Regadío } \\
1985 \text { (ha) }\end{array}$ & $\begin{array}{l}\text { Regadío } \\
2007 \text { (ha) }\end{array}$ & $\begin{array}{l}\text { Regadío } \\
2017 \text { (ha) }\end{array}$ & $\begin{array}{c}\text { Empleos } \\
\text { agrarios } 2018 \\
(n=)\end{array}$ & $\begin{array}{l}\text { Empleos } \\
\text { totales } \\
2018(n-9)\end{array}$ & $\begin{array}{c}\text { \% empleos } \\
\text { agrarios/ } \\
\text { totales (2018) }\end{array}$ & $\begin{array}{l}\text { Perceptores } \\
\text { PAC >1250 } € \\
\text { en } 2018 \text { ( } n \div)\end{array}$ & $\begin{array}{c}\text { Perceptores } \\
\text { PAC >1250 } € \\
\text { en } 2018(€)\end{array}$ \\
\hline Rueda & 38.047 & 58.604 & 3.251 & 3.918 & 22.048 & 17,8 & 2.477 & 45.841 .183 \\
\hline Ribera del Duero & 24.162 & 24.976 & 3.213 & 3.881 & 28.031 & 13,8 & 2.218 & 45.494 .004 \\
\hline Toro & 9.751 & 17.667 & 312 & 861 & 4.786 & 18,0 & 843 & 12.379 .939 \\
\hline Cigales & 4.349 & 5.245 & 640 & 343 & 4.975 & 6,9 & 284 & 5.161 .909 \\
\hline Arribes & 223 & 134 & 0 & 736 & 3.064 & 24,0 & 777 & 11.368 .871 \\
\hline Tierra del Vino & 15.431 & 24.268 & 2.597 & 1.573 & 7.364 & 21,4 & 1.747 & 26.324 .707 \\
\hline Total general & 91.963 & 130.894 & 10.013 & 11.312 & 70.268 & 16,1 & 8.346 & 146.570 .613 \\
\hline
\end{tabular}

Fuente: Junta de Castilla y León, Documentos 1-T para superficies de viñedo y regadío en 1985, 2007 y 2017; FEGA, Pagos PAC 2018, (www.fega.es); MAPA, Informes DOPs, Campaña 2017/18; INSS, Tesorería General de la Seguridad Social, Cuentas y trabajadores inscritos por régimen, municipio y actividad, clasificación CNAE 2009 a dos dígitos, en junio de 2018. Elaboración propia.

N.B.: Las superficies vitícolas de las distintas fuentes (1-T, Consejos reguladores e informes DOP) no coinciden exactamente, porque en algunos casos sólo registran las superficies en producción. 
para los dos últimos años, ha continuado creciendo a un ritmo firme en La Ribera y Rueda. Tanto es así que el Consejo Regulador de esta última denominación ha decidido frenar cautelarmente la expansión vitícola por miedo a que la producción de vino supere la demanda del mercado, pues "la superficie de viñedo en la DO Rueda se ha incrementado un 9,57\% en un año, desde las 14.753,14 hectáreas registradas en julio de 2017 a las 16.164,92 alcanzadas el pasado 31 de agosto" [de 2018] (Agronews, 2019).

Quizás se pueda pensar que esta tendencia no está consolidada, por cuanto sólo afecta a Rueda y La Ribera, ya que las demás denominaciones han perdido realmente superficie. Al margen de que este proceso se relaciona con la necesaria reestructuración del sector y su creciente adaptación e inserción en los mercados, parece obedecer a una ola expansiva general, frenada circunstancialmente por la Gran Recesión o por otras coyunturas adversas.
Sin embargo, el hecho de que bodegas como Vega Sicilia (con Pintia) o Louis Vuitton (con Numanthia Termes) estén invirtiendo en Toro, o que otras bodegas lo hagan en Cigales, como Finca Museum (del Grupo riojano Barón de Ley) o como Matarromera (bodega Valdelosfrailes), o que el marqués de Griñón lo haga en los Arribes (bodega Marqués de Griñón Hacienda Zorita)..., reafirman la idea de que los viñedos del Duero constituyen un valor seguro y un aval de éxito. Dicho éxito parte fundamentalmente de sus condiciones ecológicas, entre las que destacan el fuerte periodo de insolación, la escasez de lluvias, la rusticidad de sus suelos, la elevada altitud media de sus tierras, que combinados permiten obtener unos rendimientos escasos, pero unas cualidades orgnanolépticas excepcionales.

En este sentido, podríamos concluir que son las condiciones ecológicas, y especialmente las climáticas, las claves del éxito de los viñedos ribereños del

FIGURA 1

DISTRIBUCIÓN DEL VIÑEDO Y DEL LABRANTÍO DE SECANO Y REGADÍO EN LA MESETA NORTE Y TIERRAS PRÓXIMAS

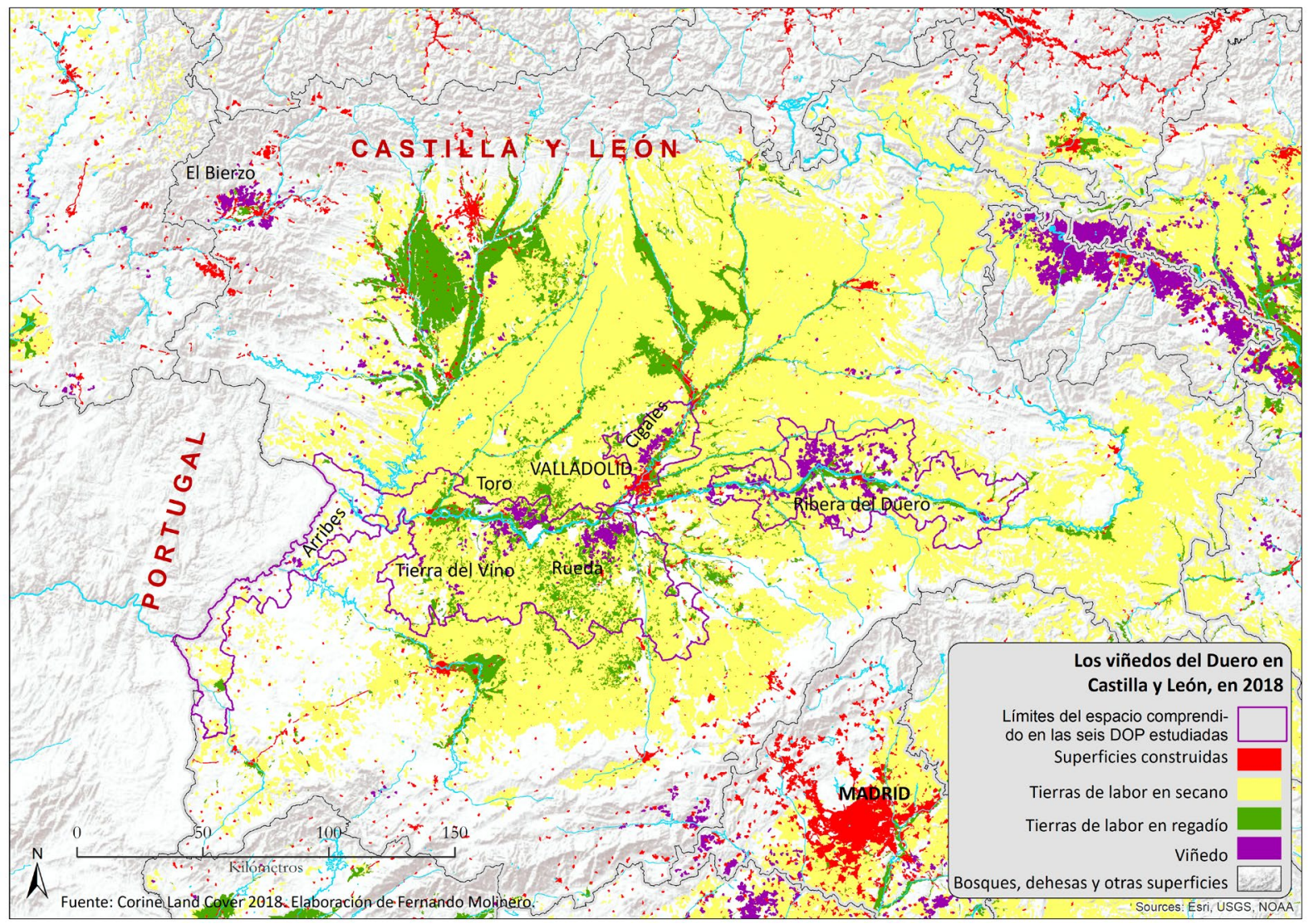

Fuente: IGN, Corine Land Cover 2018. UE, Copernicus, CLC 2018. Elaboración propia. 
Duero, unidas a unas castas (o variedades), que las encumbran, y a un continuado refinamiento y mejora enológica. Ha sido ese éxito el factor de atracción de numerosos inmigrantes y nacionales que trabajan en los viñedos y en las bodegas, tanto en el sector vitivinícola como en el del enoturismo; este último es cada vez más importante y está potenciado por el del alojamiento y restauración, especialmente por el gran auge del lechazo asado como puntal gastronómico de los restaurantes de La Ribera y de una buena parte de los del valle del Duero. Pero, antes de proceder al análisis de todo ello, es imprescindible reflexionar sobre el sentido y valor de las fuentes utilizadas.

\section{FUENTES Y METODOLOGÍA}

El estudio se basa en varios tipos de información. En primer lugar, se han utilizado fuentes documentales descriptivas del territorio, como las ortoimágenes del Corine Land Cover 2018 para conocer la extensión actual del viñedo, en comparación con los grandes aprovechamientos agrarios a escala de la Comunidad Autónoma, tal como aparecen en el Mapa 1. Así, se ha obtenido un retrato vivo de la viticultura del Duero, que ha generado un nuevo paisaje y una nueva dinámica socioeconómica. En segundo lugar, otra fuente destacable complementaria de la anterior ha sido la de los documentos 1-T sobre distribución de cultivos y aprovechamientos agrícolas a escala municipal, lo que resulta importante para conocer la evolución del viñedo y el de otras ocupaciones del suelo. Tradicionalmente, esta fuente era la base para la elaboración de los Anuarios de Estadística Agraria del Ministerio de Agricultura; se apoyaba en las declaraciones de los agricultores titulares recogidas por las cámaras oficiales sindicales agrarias locales, con las que se hacían resúmenes provinciales, más o menos ajustados. Desde que la ley de libertad sindical de 1977 y la atribución más tardía de las competencias de agricultura a las CCAA fueron difuminando la necesidad y la obligación de realizar estas tareas, algunas comunidades dejaron de cumplimentar estos documentos y se fue perdiendo poco a poco la elaboración de esta base de datos para todos los municipios de España. Algunas comunidades, como la de Castilla y León, continuaron haciéndolas y ofrecen hoy, en datos abiertos en la web, sus resultados para los años 2010 a 2017.

Para este artículo hemos dispuesto también de las bases de datos de años anteriores, recopiladas por los autores cuando todavía se elaboraban de manera sistemática. Podemos entonces establecer comparaciones entre el año 1985 -el más antiguo disponible-, el año 2007 -justo antes de la Gran Recesión, y el de 2017 -último que ofrece la Junta de Castilla y León-. Aunque estos datos se refieren al conjunto del municipio, sin precisar su localización dentro de él, se pueden considerar bastante fiables, pues se basan no sólo en las declaraciones de los agentes locales, sino, además, en las posibles correcciones realizadas merced a la utilización de imágenes de satélite (Corine Land Cover, SIOSE) y ortofotos. Para las superficies vitícolas, además, se ha contado con los Informes anuales sobre las Denominaciones de Origen Protegidas (Informes DOPs del Ministerio de Agricultura).

Junto a las fuentes documentales, referidas a las ocupaciones del suelo, se han explotado otras de carácter funcional. Éstas censan y caracterizan a los agentes del territorio, es decir, a quienes toman decisiones sobre él y lo trabajan, o sea, agricultores o empresarios agrarios y obreros agrícolas. Una de esas fuentes ha sido la base de datos SABI (Sistemas de Análisis de Balances Ibéricos), de gran interés, aunque muy incompleta y poco usada, pero útil. SABI, con una orientación hacia los balances económicos de las empresas, censa, caracteriza y aporta información fundamental de 2,5 millones de empresas de España y 0,8 millones de Portugal. Ofrece información financiera, pero también económica general y funcional, como el número de empleos de cada empresa, su evolución temporal y otras características empresariales según la clasificación nacional de actividades económicas (CNAE 2009). Permite detectar y censar las empresas de servicios agrarios. Por más que se trate de una fuente incompleta, aporta una aproximación valiosa a este tema. Por ello, y para completarla, se ha realizado trabajo de campo con entrevistas directas a empresarios y expertos conocedores y usuarios de los servicios vitivinícolas que ofertan dichas empresas. Si bien éstas aparecen en el mismo rubro y con el mismo código que las de servicios agrícolas generales, sí aparecen separadas de las que ofertan servicios a la ganadería.

En consecuencia, y para ponderar el valor y significado de los empleos agrícolas ofertados por empresas especializadas, se ha utilizado la fuente quizá más detallada: la Encuesta sobre la Estructura de las Explotaciones Agrícolas del INE, la última realizada en 2016. Permite el análisis de las explotaciones agrarias del Duero en el contexto de las de Castilla y León y de España en ese año. La Encuesta es una fuente homogénea, realizada en todos los Estados miembro (EM) 
de la Unión Europea (UE). Una vez cada 10 años, se amplía para realizar un censo completo para todo el universo muestral, mientras en el resto de los años se realizan encuestas parciales (INE, 2015, p. 9), con una muestra de en torno al $6 \%$ de las explotaciones, tratada con el mismo método en los distintos países de la UE. Así, se dispone de una información comparable en el tiempo y en el espacio, con las lógicas diferencias inherentes a la población y al universo muestral. En este trabajo se comparan los resultados de la Encuesta de 1997 con los de 2016, dos decenios posteriores, para comprobar la evolución, especialmente en lo relativo al incremento del número de asalariados agrarios a escala municipal, dato clave y complementario del auge de las empresas de servicios agrarios.

El INE proporciona los resultados de las explotaciones integrantes de la fracción muestral en cada municipio seleccionado. A cada explotación le otorga un "factor de elevación", determinado por los técnicos del INE según el grado de representatividad de cada explotación analizada. Este factor es el coeficiente por el que hay que multiplicar la explotación muestral para obtener el resultado de todas las representadas en cada estrato y rango. Por estratos, entran en la muestra todas las más grandes, mientras que en los estratos medios y bajos cada explotación seleccionada representa a un mayor o menor número de otras, según su tamaño y según su rango u orientación técnico-económica (OTE). De este modo, la muestra que el INE recoge para España alcanza las 59.290 explotaciones para un total de 945.024 (6,27\%), mientras que en Castilla y León utiliza 5.761 sobre un total de 92.083 (6,25\%).

En los estratos altos, es decir, en las grandes explotaciones agrícolas o ganaderas, la muestra es exhaustiva (factor de elevación $=1$ ). Están representadas todas. Este hecho favorece la consecución del objetivo de este artículo, que es el análisis de las empresas agrarias modernas, con empleo de mano de obra asalariada, bien fija, como sucede en las grandes explotaciones, o bien eventual. Ha sido la demanda de mano de obra temporal el factor clave del desarrollo y expansión de las empresas de servicios laborales que cotizan a la Seguridad Social por la rama de agricultura. No aparecen registradas como explotaciones agrícolas, sino como empresas de servicios agrarios bajo la forma de Sociedades Limitadas de titularidad Unipersonal (SLU). Se trata de un tipo de empresa creciente, sobre todo en las ramas agrarias muy exigentes en mano de obra, como en la horticultura, la fruticultura, la viticultura, además de en la olivicultura y en algunos otros aprovechamientos intensivos. En el caso de Castilla y
León se distribuyen con cierta homogeneidad, salvo en las áreas de ganadería extensiva. Muestran un cierto grado de concentración en las comarcas del Carracillo-Pinares (centro de Segovia/sur de Valladolid) y en el eje del Duero, precisamente en función de esa mayor demanda de mano de obra por los cultivos o aprovechamientos intensivos. Para poder comparar el papel de la mano de obra asalariada en las comarcas de OTE intensiva, se han elaborado unos mapas temáticos para el conjunto de los municipios de España, en los que se ve bien la concentración de los asalariados en las tierras donde domina la horticultura, fruticultura y olivicultura, además de la viticultura.

Metodológicamente, en relación con el análisis y tratamiento cartográfico de la mano de obra asalaria$\mathrm{da}$, se deben destacar otras cuestiones, unas relacionadas con las bases de datos y otras, con su representación cartográfica. Respecto a las primeras, el INE proporciona ficheros de microdatos que recogen las explotaciones muestrales por estratos y por municipios y OTE. Para el correcto tratamiento de estas bases, se debe aplicar el factor de elevación a todas las variables absolutas, antes de su manipulación estadística, para que cada explotación muestral sea tratada como el conjunto de explotaciones a las que representa. El paso siguiente consiste en aplicar a las explotaciones muestrales, multiplicadas por su factor de elevación, una tabla dinámica para hacer resúmenes, por municipio, de todas esas variables. Estos resúmenes son los que permiten cartografiar cualquier variable. Con este procedimiento, se consigue convertir la fracción muestral en universo poblacional.

Sin embargo, todavía persiste la dificultad de su representación cartográfica, ya que, tanto si se quiere representar el territorio nacional o el regional, es preciso cubrir los 8.124 municipios de España (en 2018), o los 2.248 de Castilla y León, con una base de datos muestral de 6.946 municipios en España, o de 1.742 en Castilla y León. Para cubrir los vacíos que dejan los 1.178 municipios de España que no aparecen en la muestra, se ha recurrido a hallar los valores de cada variable a escala comarcal y a asignar a los municipios no muestrales los valores medios o dominantes en su comarca, poniendo la capa comarcal por debajo de la de municipios, a fin de eliminar los vacíos en los mapas de coropletas. Mientras, en los mapas de figuras proporcionales sólo aparecen los valores de los municipios muestrales, pero siempre multiplicados por su factor de elevación, por lo que realmente representan al conjunto de municipios de Castilla y León, o de España, en su caso. 
Para aprovechar mejor esta información, hemos cruzado, en la medida de lo posible, los datos sobre ocupaciones del suelo con los de empleo agrario en 2018, proporcionados por la Tesorería General de la Seguridad Social a escala municipal, clasificados a dos dígitos según la CNAE 2009. Hemos confrontado estas bases anónimas de la Seguridad Social con las listas nominales de los perceptores de ayudas PAC en cada municipio. Realmente, los cotizantes a la Seguridad Social por la rama de agricultura representan el valor más fiable, en cuanto datos de empleo agrario a escala municipal. Al tratarse de datos anónimos, sólo proporcionan el número total de empleos a dicha escala, tanto de empleadores como de empleados, es decir, de agricultores titulares o de obreros agrícolas. Ahora bien, sumando, cruzando o combinando todas estas variables, se ha podido conseguir una visión panorámica de las explotaciones agrarias de Castilla y León -y de su peso en el territorio de España-, y de su valor y significado en los municipios y espacios vitícolas del Duero, así como de la porción o parte de esas empresas y empleos asalariados en el conjunto del empleo.

En suma, desde la perspectiva metodológica, se han utilizado las bases de datos y fuentes oficiales y privadas para analizar la expansión de la viticultura en el valle del Duero desde los años 1980 para estudiar cómo, merced a la nueva explotación vitícola -mejor dimensionada y adaptada a las demandas del mercado actual-, se ha creado un territorio vitivinícola de calidad mundial que ha cambiado completamente las condiciones socioeconómicas de los pueblos ribereños. En este contexto han surgido las empresas de servicios a la viticultura, que representan uno de los motores de estos viñedos de calidad. Obviamente, la caracterización de esta nueva viticultura ha exigido realizar un trabajo de campo extenso, que se ha llevado a cabo mediante entrevistas a bodegueros, a viticultores y a empresarios empleadores, quienes conocen -mejor que nadie- las características, la dinámica y los problemas de los viñedos y de los pueblos del Duero.

\section{RESULTADOS: LA EMERGENCIA DE NUEVOS MODELOS LABORALES Y LA EXPANSIÓN DE LOS ASALARIADOS AGRÍCOLAS}

La nueva viticultura del valle y campiñas del Duero sorprende por su fuerte dinamismo, sin parangón con el resto del territorio vitícola europeo. El auge espectacular de la DOP Rueda, a un ritmo de unas 1000 hectáreas por año durante los últimos cinco años, así como el crecimiento sostenido de La Ribera, se deben a su valoración creciente en el mercado nacional e internacional, por un lado, y a una renovación profunda de sus espacios vitícolas respectivos, de sus técnicas agronómicas, de la forma de conducción del viñedo, de la organización del trabajo y de la abundante mano de obra inmigrante, por otro. Esta mano de obra ha encontrado en La Ribera y Rueda unos ámbitos de trabajo muy atractivos, en los que han surgido unos tipos de empresas de servicios vitícolas fuertes, versátiles y expansivos, cubiertos fundamentalmente por inmigrantes, generalmente en forma de Sociedades Limitadas Unipersonales (SLU). Es un tipo de empresa que se ha extendido por todas las regiones de España, pero sólo para los cultivos o aprovechamientos intensivos.

Aunque es difícil censar estas empresas, están inscritas en el Registro Mercantil Central, donde se da cuenta de su creciente importancia. Así, si en 2012 el $32 \%$ de las sociedades constituidas en España eran unipersonales (en todas las ramas de la economía, no sólo en la agraria), en el 2018 esa tasa ascendía al $42 \%$. Ello supuso la creación de 39.346 SLU en toda España, cuyo número total ascendía a 570.004, de las que 26.039 correspondían a Castilla y León, especialmente a la provincia de Valladolid, que acapara más de la cuarta parte (RMC, 2019, pp. 43-48). Al margen de su forma social -en gran medida relacionada con la reforma laboral de 2012, que les permite dar fácilmente de alta y de baja a cada trabajador a través de Internet-, interesa saber dónde se localizan, precisamente porque tienden a hacerlo en las comarcas con aprovechamientos más demandantes de mano de obra, lo que nos obliga a cartografiar las Orientaciones Técnico-Económicas, o aprovechamientos dominantes en cada comarca. Así, hemos cartografiado las OTE comarcales, a las que hemos superpuesto la información individual de cada empresa, a escala municipal, aportada por la base de datos SABI, con una descripción mucho más detallada que la del RMC.

\section{Las empresas de servicios como organización ágil para las labores vitícolas}

El tipo más destacable de empresas laborales vitícolas corresponde a las que ofrecen servicios técnicos y de mano de obra; un segundo tipo aporta sólo mano de obra, más o menos especializada; un tercero, los autónomos en servicios de apoyo a la agricul- 
tura, que ofrecen los mismos servicios agrarios que otras empresas más grandes, pero a pequeña escala, para conseguir una remuneración mayor que la percibida mediante el trabajo por cuenta ajena. Las primeras empresas suelen ser más antiguas y capitalizadas; las segundas han surgido al calor de las coyunturas de reestructuración y expansión del viñedo desde 2004; las terceras son más recientes y responden al lógico deseo de remunerar más y mejor al trabajo propio, pues suelen ser antiguos asalariados que se hacen autónomos o que forman su propia SLU, para emplearse a sí mismos y a sus familiares y allegados.

De entrada, realizamos una aproximación a partir de la base de datos SABI. A pesar de que se trata de una base incompleta, permite un acercamiento valioso, tanto más cuanto que, al cartografiar los resultados, ofrece una visión de conjunto sobre la distribu- ción territorial de las empresas de servicios de apoyo a la agricultura. Así, de las 342 registradas en Castilla y León en octubre de 2019, la mayor parte corresponde a la rama agrícola y se distribuyen con cierta homogeneidad por todo el territorio castellanoleonés. Al contrario, el número de obreros evidencia una extraordinaria concentración en pocos municipios y comarcas. Los mapas (Figuras 2 y 3 ) lo reflejan claramente, con Rueda y La Ribera como sede del mayor número de empresas de servicios agrarios, secundadas por el municipio de Valladolid y, fuera de este ámbito, abundan en las áreas de ganadería intensiva, con Segovia capital a la cabeza, a las que se añaden, en ramas no vitícolas, Benavente, el municipio abulense de Niharra ${ }^{2}$ y Palencia capital.

Si analizamos la Figura 3, se aprecia la desigual distribución de los empleos en la rama agrícola con respecto a la ganadera, con un claro predominio de

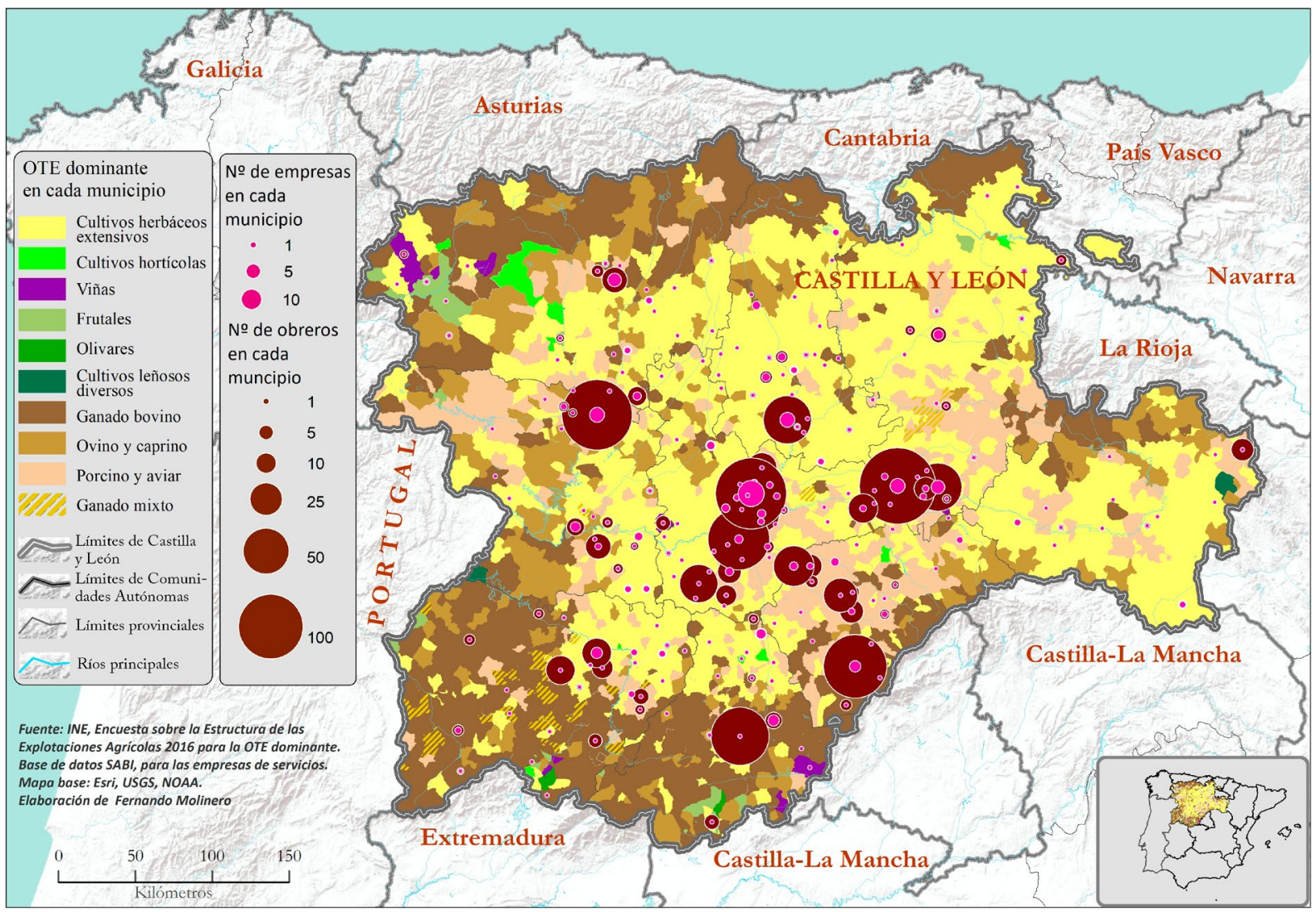

Fuente: INE, Encuesta sobre la Estructura de las Explotaciones Agrícolas 2016 para la OTE dominante; Base de Datos SABI 2019 para las empresas de servicios. Elaboración propia. 
aquélla, especialmente en la franja del valle del río Duero y en Rueda. Se ve el papel preponderante de los obreros dedicados a los servicios ganaderos en la provincia de Segovia, secundados levemente por los de Salamanca (círculos verdes de la Figura 3), además de en Valladolid, Laguna de Duero, Palencia y Benavente. Esta distribución es concordante con los aprovechamientos dominantes en cada comarca, pues tanto Segovia como Salamanca se orientan al porcino -intensivo y extensivo respectivamente-, mientras que en el resto de la Comunidad aparecen algunas empresas en municipios aislados. En todo caso, estas empresas de servicios de apoyo a la agricultura o ganadería muestran una expansión firme, sobre todo en el caso del viñedo.

Para tener una visión general, en la Tabla 2 se hace una valoración cuantitativa del conjunto de las empresas censadas, con su número de operarios, por provincias y con detalle comarcal para las áreas DOP del valle del Duero. Faltan numerosas empresas de autónomos o de PYMES que no aparecen en la base $\mathrm{SABI}$, tal como hemos podido comprobar durante el trabajo de campo. Sin embargo, su distribución general permite una buena aproximación. También debemos destacar que el trabajo de campo nos ha permitido constatar que los empresarios declaran un número medio de obreros anuales inferior al que realmente utilizan: primero, porque no todos los obreros son fijos y, segundo, porque muchos de ellos trabajan esporádica o eventualmente y sólo figuran cuando suman un elevado número de jornadas trabajadas al mes. En todo caso, se trata de empresas que representan un nuevo modelo sociolaboral, emergente, expansivo y tendente a la consolidación, cuyo número de obreros varía estacionalmente en función de las necesidades laborales; es un número

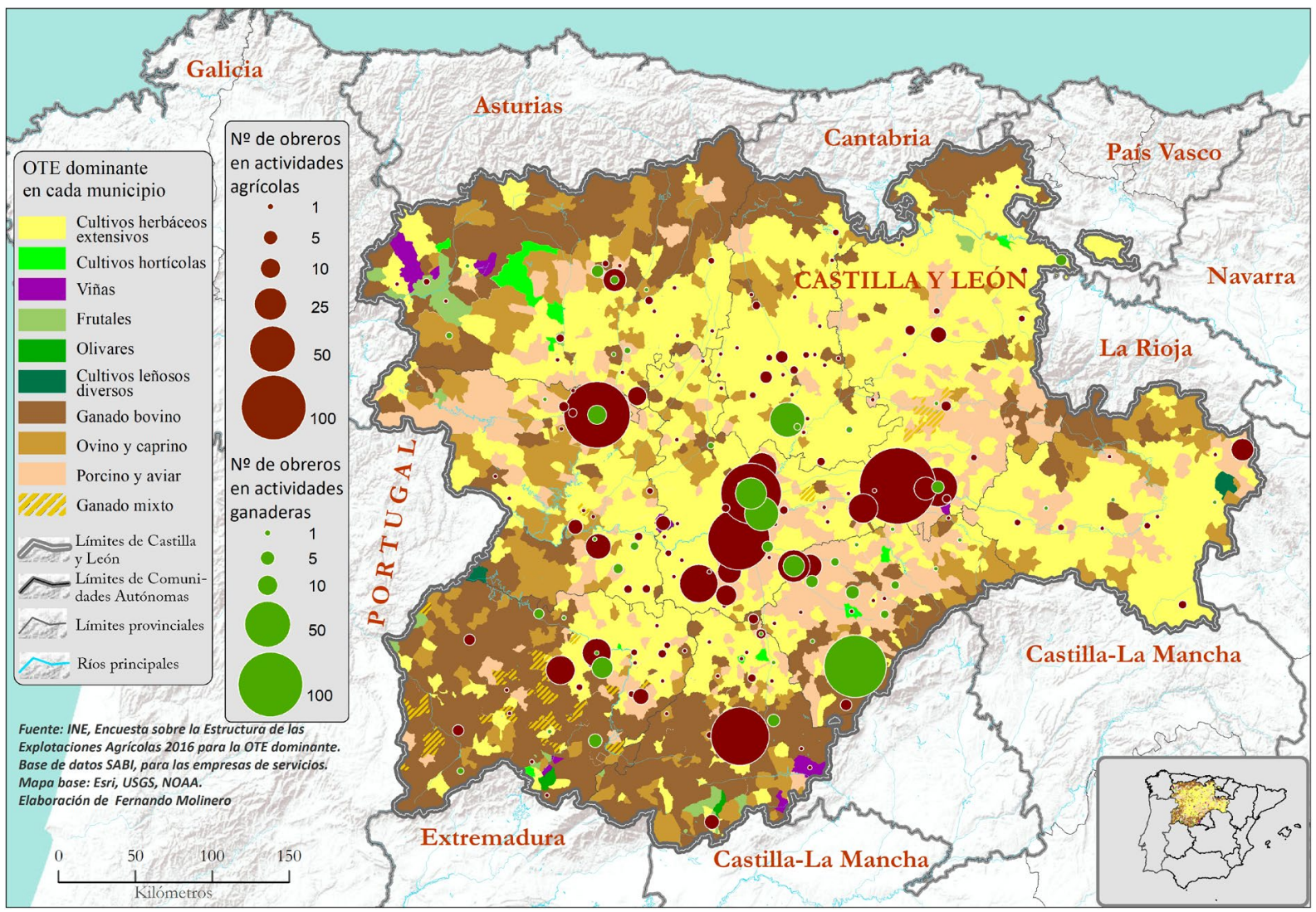

Fuente: INE, Encuesta sobre la Estructura de las Explotaciones Agrícolas 2016 para la OTE dominante; Base de Datos SABI 2019 para las empresas de servicios. Elaboración propia. 
optimizado merced a las ventajas que ofrece el actual marco de contratación.

De esta aproximación general, cabe destacar algunos casos de empresas que ofrecen servicios integrales a la viticultura, bien por su magnitud o por su singularidad. Sobresale, entre todas, la empresa familiar DALMADEL, con 39 empleados fijos declarados, que desarrolla un amplio abanico de actividades muy distintas a las demás. Es un ejemplo de empresa especializada de capital autóctono, surgida en la localidad de Serrada (Valladolid). Al calor de la expansión del viñedo, de la llegada de "derechos" de plantación vitícola de otras comunidades y de las ayudas a la mejora y reestructuración del viñedo, alentadas y subvencionadas por la UE desde 2004 , se ha equipado con 20 potentes máquinas vendimiadoras y con unos cuantos tractores de gran potencia y dotados de GPS. Sin necesidad de conductor, van implantando los "palos" en las parcelas de las terrazas, campiñas, vegas y páramos de las franjas durienses. De este modo, se ha hecho una renovación total de las castas, variedades o cepaje tradicional, sustituyendo al Jerez Palomino por el verdejo, al tiempo que se ha abandonado el antiguo modo de conducción de la cepa en copa (vaso) por el de espaldera, sumado a la fortísima expansión de las viñas en los campos cerealistas de Rueda.

Esta empresa, que convierte las máquinas vendimiadoras en cosechadoras de aceituna durante la zafra en Extremadura, Andalucía y el Algarve (sur de Portugal), es un ejemplo de una potente empresa de apoyo a la agricultura, que ha sabido explotar la ex-

TABLA 2

DISTRIBUCIÓN PROVINCIAL (CON DETALLE DE LAS COMARCAS VITÍCOLAS DEL DUERO) DE LAS EMPRESAS Y EMPLEADOS EN ACTIVIDADES DE APOYO A LA AGRICULTURA Y GANADERÍA EN CASTILLA Y LEÓN EN 2019

\begin{tabular}{|c|c|c|c|c|c|c|}
\hline \multirow[b]{2}{*}{ PROVINCIA } & \multicolumn{2}{|c|}{ Apoyo a la agricultura } & \multicolumn{2}{|c|}{ Apoyo a la ganadería y otros } & \multicolumn{2}{|c|}{ Total provincial } \\
\hline & № empresas & № obreros & № empresas & № obreros & № empresas & № obreros \\
\hline Ávila & 20 & 118 & 3 & 8 & 23 & 126 \\
\hline Burgos & 37 & 309 & 5 & 24 & 42 & 333 \\
\hline León & 25 & 55 & 9 & 19 & 34 & 74 \\
\hline Palencia & 37 & 50 & 5 & 59 & 42 & 109 \\
\hline Salamanca & 26 & 89 & 8 & 35 & 34 & 124 \\
\hline Segovia & 14 & 34 & 18 & 177 & 32 & 211 \\
\hline Soria & 11 & 29 & 4 & 4 & 15 & 33 \\
\hline Valladolid & 73 & 405 & 10 & 87 & 83 & 492 \\
\hline Zamora & 30 & 167 & 8 & 30 & 38 & 197 \\
\hline Total general & 273 & 1256 & 70 & 443 & 343 & 1699 \\
\hline \multicolumn{7}{|c|}{ № de obreros agrícolas registrados en las 6 DOP vitícolas del valle del Duero, por provincias } \\
\hline Provincia & RUEDA & RIBERA & TORO & CIGALES & ARRIBES & TIERRA VINO \\
\hline \multicolumn{7}{|l|}{ Ávila } \\
\hline Burgos & & 299 & & & & \\
\hline \multicolumn{7}{|l|}{ León } \\
\hline \multicolumn{7}{|l|}{ Palencia } \\
\hline \multicolumn{7}{|l|}{ Salamanca } \\
\hline Segovia & 2 & 1 & & & & \\
\hline Soria & & 3 & & & & \\
\hline Valladolid & 188 & 29 & 2 & 29 & & \\
\hline Zamora & & & 18 & & & 34 \\
\hline Total general & 190 & 332 & 20 & 29 & 0 & 34 \\
\hline
\end{tabular}

Fuente: SABI, Castilla y León, octubre 2019. Elaboración propia. 
celente coyuntura surgida a principios de siglo merced a las ayudas europeas para la renovación del viñedo. De hecho, la clave de su capitalización y expansión estuvo en los planes de la Unión Europea para la reconversión varietal, como estudia brillantemente Esteban de Íscar (2015, pp. 988-1091). Merced a la subvención de un $40 \%$ de los costes de transformación, tanto las explotaciones familiares como las empresariales se embarcaron en un proceso de renovación, sustitución y ampliación del viñedo, que ha densificado extraordinariamente las campiñas suddurienses y que ha permitido a Rueda alcanzar las casi 16.200 ha actuales y superar a La Ribera en producción de uva y vino.

El viñedo llega modificando completa y a gran escala el paisaje a partir del año 2000, lo que supuso toda una "revolución" impensable en estos términos unos años antes. Los viejos viñedos a marco real se sustituyeron, en un plazo relativamente muy breve de tiempo, por el sistema de conducción en espaldera. La transformación se enmarcó, por un lado, en la potenciación de la varietal verdeja y, por otro, en la asunción de la conducción en espaldera como la más idónea en las distintas prácticas culturales que lleva el arbusto, especialmente en la vendimia nocturna, facilitando, de esta manera, la extracción de todo el potencial aromático de la varietal en las mejores condiciones.

Aunque las primeras espalderas se montan en la DO Rueda en la segunda mitad de los setenta, la gran transformación tiene lugar veinte años después, especialmente al amparo de las ayudas emanadas de los Planes de Reestructuración y Reconversión de Viñedo convocadas por la Consejería de Agricultura y Ganadería de la Junta de Castilla y León. ${ }^{3}$ Estas ayudas vienen enmarcadas de acuerdo al reglamento $\mathrm{CE}$ 1493/1999, del Consejo de 17 de mayo, sobre la Organización Común del Mercado Vitivinícola, que trata de fomentar la obtención de vinos de calidad para conseguir así la máxima competitividad, mantener la renta de los agricultores y favorecer la diversidad regional del cultivo. ${ }^{4}$ (Esteban de Íscar, 2015, p. 1073).

Esta reconversión, clave del desarrollo de estas empresas, viene siendo apoyada con planes quinquenales de ayudas en toda la UE, cuya regulación actual en materia vitivinícola se engloba en el Reglamento (UE) no 1308/2013 del Parlamento Europeo y del Consejo, de 17 de diciembre de 2013. Según el Fondo Español de Garantía Agraria -FEGA- ${ }^{5}$ la sección 4 del citado Reglamento describe los programas de apoyo al sector vitivinícola que cada Estado miembro puede aplicar.
Entre Las medidas elegibles figuran la promoción de vino en terceros países, la reestructuración y reconversión del viñedo, la cosecha en verde y la destilación de subproductos. En cuanto a la reestructuración y reconversión, su artículo 46 dice que "tiene como finalidad aumentar la competitividad de los productores vitivinícolas y se articula a través del apoyo a tres actividades: reimplantación del viñedo, reconversión varietal y mejora de las técnicas de gestión del viñedo. Pueden ser beneficiarios de la medida los viticultores o futuros viticultores cuyos viñedos se destinen a la producción de uva para vinificación. Asimismo, se contempla la replantación de viñedos tras arranque obligatorio por motivos sanitarios o fitosanitarios, por orden de la autoridad competente."

Pero en Serrada, La Seca, Rueda, Medina del Campo..., abundan también otras empresas de menor entidad que las comentadas, aunque algunas alcanzan hasta 200 obreros empleados a lo largo de casi todo el año, salvo finales de octubre y noviembre. Como ejemplos destacables aportamos los proporcionados por el empresario autóctono y estudioso de los viñedos de Serrada (Miguel Esteban de Íscar), ${ }^{6}$ quien destaca el papel de Vod Vinegarden SLU. Con sede en Serrada, inicia su andadura en 2013 con labores manuales vitícolas y hace unos años amplió sus servicios, adquiriendo dos máquinas de vendimiar, tractores, etc., además de invertir en viñedo: tiene cerca de 100 ha en los términos de Nava del Rey y Medina del Campo. Puede contar entre 15 y 150 trabajadores, según sean las distintas labores temporales que requiere la vid. ${ }^{7} \mathrm{Vi}$ negarden se especializa en injertos y sobreinjertos aéreos (en yema), montaje de espalderas, producción de cultivos de vid, poda en seco y poda en verde. Su administrador único es rumano, lo mismo que el de Servicios Agrícolas Lucian SLU, creada en 2017, de dimensiones más modestas. También en 2013 se constituyó DARSERV 2013, SL, con sede en Olmedo, que emplea a más de 11 obreros.

Estas empresas, como otras de menor entidad, de capital español o rumano, se crean merced a la fuerte demanda de servicios vitícolas, tanto por parte de empresarios bodegueros como de particulares. Están formadas por empleados cualificados integrantes de cuadrillas de asalariados pertenecientes a bodegas o a empresas de servicios existentes previamente, de las que se segregan para constituir su propia SLU. Su número de trabajadores fluctúa estacionalmente según las tareas a realizar en el viñedo, pasando de decenas de trabajadores, en los meses de menor actividad, a más de 50, 100 o 200 empleados cada 
una durante la poda en verde. Parte de sus trabajadores temporales tienen fijada su residencia en la comarca desde hace años. Durante los últimos años se han creado bastantes sociedades limitadas unipersonales en torno a un núcleo familiar o de amigos, que incluso organizan la llegada de otros parientes y conocidos desde Rumanía o de Bulgaria cuando más mano de obra se necesita, en los meses de abril, mayo y junio.

Frente a Rueda, en la Ribera del Duero destaca, muy por encima de las demás, la SLU Bonifacio Santamaría registrada en Roa. Esta villa, sede del Consejo Regulador, ha crecido extraordinariamente. Así, la base SABI censa ocho empresas de servicios vitícolas, de las que tres están regentadas por rumanos o búlgaros. Aunque en La Ribera ha habido un menor impulso transformador del viñedo, el fenómeno ha corrido parejo al de Rueda, si bien la vendimia mecanizada sólo afecta aquí a una cuarta parte del total de la producción. La empresa más potente es la citada BONIFACIO SANTAMARÍA, que controla aproximadamente el trabajo completo de un $6 \%$ de los viñedos de La Ribera (unas 1750 ha). Surgió en el año 2009 por decisión personal de un antiguo capataz de labores vitícolas, que dio el salto al empresariado a partir de la gestión del trabajo de entre 50 y 200 trabajadores, según la época del año. Estos obreros, originarios fundamentalmente de los países de Europa oriental, se completan con un $20 \%$ de origen magrebí y un 8 a 10\% de españoles. No es de extrañar que, ante las facilidades que dio la Reforma Laboral de 2012, los propios rumanos hayan constituido sus propias empresas, con familiares y allegados, a quienes dan de alta en la Seguridad Social y liquidan sus cotizaciones al organismo a fin de mes, por los días trabajados, mediante procedimientos telemáticos.

Otra empresa destacable es CASTILLA SERVICIOS AGRARIOS SL, creada en 2012 en Nava de Roa (Burgos), con 18 obreros. Cuenta con máquinas vendimiadoras y ofrece todo tipo de servicios vitícolas (datos obtenidos de SABI, 2019).

Un caso singular está representado por la empresa VOCARRAJE, con sede en Morales de Toro (Zamora), que declara 8 obreros y que representa una situación intermedia, pues cuenta, además, con bodega familiar. Tal como figura en su página web, "el fundador de la bodega, Abdón Segovia, ejerce la labor de gerente enólogo y ha dedicado su vida a la viticultura trabajando para las más prestigiosas bodegas del país, y es el que ha atraído a la DO Toro a bodegueros importantes de otras denominaciones, como al de
Vega Sicilia, Marqués de Riscal, Mauro y un largo etc." ${ }^{8}$ Está, además, asociado con el prestigioso marchante francés Magrez, con quien elabora vinos del Domaine Magrez Espagne. La empresa de SERVICIOS VITIVINICOLAS VOCARRAJE fue fundada en 1980, cuando todavía no existía la DO. En ese momento, prestaba servicios de poda (en seco) y otras labores a los viticultores toresanos con trabajadores de los pueblos de la comarca. Fue ampliando su campo de acción y, cuando llegó el boom del viñedo y su reconversión, se dedicó a realizar todo tipo de labores vitícolas, con empleo de mano de obra inmigrante, entre la que destacan los rumanos. De hecho, hay una colonia de rumanos empadronada en Morales de Toro. Obviamente, estos trabajadores son requeridos masivamente en los momentos de mayor actividad (poda en verde, vendimia y poda). ${ }^{9}$

Ambos tipos de empresas -la del español Bonifacio Santamaría y las de los rumanos- se acompañan de otras muchas, de tamaño medio y pequeño. Aportan máquinas y mano de obra a prácticamente el $100 \%$ de los viticultores del Duero. Han proliferado enormemente $y$, ante la fuerte demanda de trabajo en el sector, han planteado unas relaciones laborales singulares y duras.

\section{Una mano de obra inmigrante, integrada fundamentalmente por rumanos y búlgaros}

La mano de obra ha sido de aluvión, movida por una demanda creciente, que acompaña al auge vitícola, tal como planteábamos en el XII Coloquio CIER celebrado en Segovia en 2018, cuyas aportaciones recogemos en este apartado (Molinero y Martínez, 2018). En palabras de Esteban de Íscar, "sin esta mano de obra no se podría practicar la viticultura que hoy conocemos". Ésta se basa en la aportación masiva de trabajo por parte de inmigrantes en condiciones laborales duras, con remuneración económica baja y en condiciones sociales y habitacionales precarias. Al margen de la diversidad de situaciones y del distinto trato de los empresarios, hay hechos básicos incuestionables, como una remuneración parca, una cotización a la seguridad social un tanto descontrolada y unas condiciones de vivienda y desarrollo personal difíciles.

La empresa de Bonifacio Santamaría representa bien al empresario de entidad: 60 obreros de media durante todo el año (de los que 30 son fijos). Ascienden hasta 250 en la época de vendimia (desde finales 
de septiembre hasta finales de octubre), lo que se reduce a unos 30 en los momentos de mínima actividad, entre finales de octubre y noviembre, pues la poda se empieza en diciembre, cuando ha caído la hoja.

Al margen de que el trimestre invernal es aprovechado para la poda, los cuidados son constantes a partir de ese momento, con la limpieza de los alambres de las espalderas y su mantenimiento, junto con el arreglo de los brazos de la vid. Así, entre diciembre y junio, las cuadrillas de obreros andan rodando por las viñas sin parar. A las labores de poda, barrido de vástagos y limpieza de alambres le siguen las de eliminación de chupones (brotes sin fruto, fuera de lugar), las de poda en verde (eliminación de exceso de tallos), las de bajada de alambres y su subida posterior durante al menos dos veces en primavera, y las de "desnietado" (eliminación de tallos adventicios que brotan de los principales); todo ello sin contar el trabajo de arado para eliminación de hierbas, ni los tratamientos fitosanitarios. Así, el cuidado de las 23.000 ha de La Ribera y las 16.500 de Rueda exige unas 20 jornadas por hectárea durante los seis primeros meses del año, lo que se aproxima a un millón de jornales, la mitad de los cuales al menos procede de los inmigrantes, mientras el resto de los viticultores titulares. Estacionalmente, las exigencias de mano de obra en los viñedos del Duero responden al patrón comentado, si bien en los de Rueda se ahorran unos 5 jornales de la vendimia, que se realiza casi totalmente con máquina, puesto que una vendimiadora tan sólo invierte dos horas por hectárea.

El ciclo comienza con la poda, aunque se suele hacer previamente la prepoda, pasando un tractor por el centro de la calle, con un apero de dos ejes verticales, sobre los que giran discos dentados troceadores que enganchan los palos largos de cada lado del linio, los cortan y dejan en el suelo. A esa labor mecanizada le sigue la de limpieza de alambres y recogida de vástagos de la vid, el mantenimiento y tensión de los alambres, la poda propiamente dicha, la subida de los alambres para la sujeción de los vástagos de la vid en primavera, el desvastigado y desnietado para eliminar la exuberante vegetación de la vid y permitir el soleado de la cepa, la vendimia en verde, la vendimia manual (o mecanizada) y el traslado de los racimos a la bodega. La vid exige cuidados y atenciones continuas, desde diciembre hasta mediados o finales de octubre. A todo ello hay que sumar los tratamientos fitosanitarios realizados con el tractor $y$ los pases de arado para eliminar hierbas.
A continuación, se detallan las labores y calculamos sus costes.

- Poda. se realiza entre noviembre/diciembre y marzo/abril. Se cortan los sarmientos; se sacan al centro de la calle y se atan o empacan. Consume entre 40 y 48 horas/ha, equivalentes a entre 5 y 6 jornadas. Supone un coste de unos $400 €$. La conducción más extendida actualmente ha sido la de espaldera, con dos brazos, uno a cada lado de la cepa. En cada brazo se dejan tres palos, con entre tres y cinco yemas cada uno; de cada yema se puede obtener un racimo.

- Reparación de alambres, reposición de brazos y cabezas de la cepa. 1 jornada/ha (80 €). Esta labor se realiza desde finales de noviembre, cuando el frío y alguna helada han hecho caer la hoja. Es un trabajo enteramente manual y, en cierto modo, especializado.

- Poda en verde (espergura). Se realiza entre mayo y junio, para dejar sólo los tallos fructíferos, con los racimos seleccionados. Consume entre 24 y 28 horas de trabajo/ha, unas 3 jornadas (unos $280 €)$. Es la época del año de máxima demanda de mano de obra, junto con la vendimia. Normalmente se eliminan los racimos más raquíticos o los que muestran algún defecto físico. Dada la ubérrima producción de la vid, conviene eliminar bastantes racimos para no superar los rendimientos marcados por los Consejos Reguladores de las DOP.

- Subida de alambres para que los tallos se levanten erguidos entre ellos. Los alambres se bajan antes de podar para facilitar la poda y evitar roturas, y se suben dos veces posteriormente, tras haber fijado los brazos de la cepa al alambre-guía con una brida; lo que consume unas 16 horas de trabajo/ha (unos $160 €$ ). Es una operación laboriosa y necesaria para evitar que los vástagos se arrastren por el suelo y den excesiva humedad a la cepa, pues la aireación y el soleado son imprescindibles para obtener un fruto sano.

- Desnietado/deshojado. Dependiendo de la épo$\mathrm{ca}$, el desniete consume entre 24 y $40 \mathrm{~h} / \mathrm{ha}$, aunque el trabajo se reduce cuando se usa tijera. Se completa con el deshoje para airear la cepa y conseguir una mejor sanidad del producto. Consume entre 16 y 24 horas/ha, aunque no se hace siempre. La eliminación de los vástagos 
estériles ahorra nutrientes y favorece una mayor aireación, oxigenación e insolación de la cepa.

- Aclareo o vendimia en verde para la eliminación de racimos, en agosto, si las cepas vienen muy cargadas. En vinos de calidad se dejan $5000 \mathrm{~kg}$ de uva/ha (en La Ribera; en Rueda se llega a los 9.000 o 10.000). El aclareo consume 20 horas de trabajo y hasta $40 \mathrm{~h} / \mathrm{ha}$ si es intensivo (unos $300 €$ ). Recientemente, el Consejo Regulador de Rueda ha decidido rebajar un $10 \%$ el techo de rendimiento para reducir la producción general de la DOP.

- Vendimia mecanizada. Para que la vendimia mecanizada aporte la máxima calidad, es necesario eliminar manualmente los racimos defectuosos o que muestren signos de botritis, además de los agraces; asimismo, conviene eliminar hojas secas y otros elementos de suciedad (15 a $16 \mathrm{~h} /$ ha, unos $150 €$ ). El coste de 2 horas de máquina asciende a $400 € /$ ha. En Rueda, el $99 \%$ de la vendimia se hace mecanizadamente, mientras en la Ribera, aunque está aumentando, todavía anda por el $20 \%$.

- Vendimia manual: 40 a 48 h/ha, 5 o 6 jornales, entre 400 y $480 €$. Las bodegas prestigiosas realizan la vendimia manual en cestas o banastas de plástico, que portan unos $10 \mathrm{~kg}$ de peso, mientras que las bodegas de menos renombre descargan los cestos en remolques con lonas plastificadas. Cuando los racimos llegan a las bodegas, hay un proceso de selección y de eliminación de racimos ( $y$ hasta de bayas) por "veedores" o "veedoras" que controlan estrictamente la calidad de la uva que entra en las prensas.

- Labores de tractor para quitar hierba y aplicar tratamientos. Se da un mínimo de dos pases al año en primavera, dependiendo de las lluvias, con un arado denominado intercepa ( $2 \mathrm{~h} / \mathrm{ha} /$ pase); asimismo, se esparce azufre y sulfatos las veces que sea necesario, dependiendo igualmente del tiempo primaveral: cuantos más días de lluvia, más se reiteran los tratamientos (4 o 5 pases, unas 2 a 2,5 h/ha). Hay que sumar el esparcir abonos, tratar contra la botritis, etc. (en total, $10 \mathrm{~h} / \mathrm{ha} \times 35 € / \mathrm{h}$ ).

En La Ribera, en suma, con vendimia manual y todo tipo de cuidados, una hectárea exige 28 jornadas de trabajo (incluidas labores de tractor y tratamientos), lo que, aplicando un salario de entre 10 y $11 € /$ hora más los gastos de abonos y fitosanitarios, supone un coste de 2500 a $2700 € /$ ha, o sea el $50 \%$ del valor de la uva. Hay que tener en cuenta que, aunque hemos asignado un coste medio horario de $10 €$, éste varía

TABLA 3

LABORES VITÍCOLAS Y EXIGENCIAS DE MANO DE OBRA

\begin{tabular}{|c|c|c|c|c|}
\hline Labores manuales & Meses & Horas/ha & Jornadas/ ha/año & Coste/ha (€) \\
\hline Poda & Noviembre a abril & 40 a 48 & 5 a 6 & 400 a 480 \\
\hline $\begin{array}{l}\text { Reparación de alambres, reposición de brazos y cabezas } \\
\text { de cepa }\end{array}$ & Noviembre a abril & 8 & 1 & 80 \\
\hline Poda en verde & Mayo y junio & 24 a 28 & 3 & 280 \\
\hline Subida de alambres & Abril a junio & 16 & 2 & 160 \\
\hline Desnietado y deshojado & Junio a agosto & 40 a 64 & 5 a 8 & 500 \\
\hline Aclareo / vendimia en verde & Agosto & 30 & 3 a 4 & 300 \\
\hline Vendimia manual & octubre & 40 a 48 & 5 a 6 & 480 \\
\hline \multicolumn{5}{|l|}{ Labores de tractor / vendimiadora } \\
\hline Vendimia mecanizada & Septiembre/ octubre & 2 & 0,2 & 400 \\
\hline Quitar hierba (varios pases) & Abril, mayo... & 5 & 0,5 & 175 \\
\hline Azufrar y sulfatar ( 5 pases) & Junio a agosto & 3 & 0,4 & 105 \\
\hline Abonar y tratar botritis & Variable & 2 & 0,2 & 70 \\
\hline Total mano de obra & Todos los del año & 210 a 254 & 19,3 a 31,3 & 2950 a 3030 \\
\hline
\end{tabular}

Fuente: elaboración propia a partir de entrevistas con empresarios y viticultores, con mención especial a Bonifacio Santamaría Pinillos (Roa), Miguel Esteban de Íscar (Serrada), Alfonso Redondo Gil (Peñafiel) y Epifanio García del Pozo (Olivares de Duero). 
según el momento del año; es más caro en vendimias y más barato en el trimestre invernal. El coste se eleva a $12 € / h$ durante la poda en verde y baja hasta 8 en noviembre. En Rueda, por otro lado, se pagan $2 €$ menos por hora que en La Ribera. En Toro, Cigales, Tierra del Vino y Arribes hay menos demanda de trabajo y menos oferta de las empresas, como se aprecia en la Tabla 2.

Uno de los graves problemas de esta mano de obra es la temporalidad, por cuanto el trabajo del campo es, por naturaleza, estacional. Tiene la ventaja de que se distribuye bastante bien a lo largo del año, incluido el invierno, cuando, a pesar de la menor presión, se realizan las labores de poda. Por ello, los obreros encuentran su nicho laboral sin problemas durante todo el año. No obstante, la dureza del trabajo es una nota general sin queja; entre otras razones, porque se trata de adultos jóvenes y maduros, que toleran bien las intensas y largas jornadas laborales a la intemperie.

Pero quizá el mayor problema radica en la remuneración. Bonifacio Santamaría se quejaba de la competencia desleal en este asunto, ya que a menudo se organizan pequeñas empresas que dan de alta en la Seguridad Social a un número de obreros menor que el utilizado, sin que haya inspecciones de trabajo que lo eviten. El principal problema es que la liquidación de cotizaciones la realiza el empresario a final de cada mes y, si hay connivencia con los obreros, éstos pueden cobrar más (en negro) a costa de que el empleador declare menos horas o días trabajados. Aunque sea cierto que se tiende a legalizar esta situación, todavía quedan prácticas perversas. Como el coste del Seguro Social supone aproximadamente un $28,3 \%$ de la nómina mensual del trabajador, el empresario puede ahorrarse en torno a $300 €$ al mes por cada obrero que no registre, lo que, en una cuadrilla grande puede ascender a $3.000 € /$ mes si deja de declarar a 10 obreros. El diferencial, por otro lado, entre lo que el empresario factura al viticultor o bodeguero y lo que el obrero percibe, suele ser de $2 €$ por hora. En palabras de Santamaría, la situación idónea consistiría en facturar a $15 €$ /hora/obrero y remunerar al trabajador con unos 12,5 a $13 €$ /hora, lo que permitiría cubrir el pago a la Seguridad Social, el gasto en transporte de los obreros al campo y dejar un beneficio al empresario por el servicio y la gestión.

Una empresa de similares características a la de Bonifacio Santamaría es la de Vod Vinegarden en Serrada, creada por un emprendedor rumano que, aprovechando su capacidad de gestión, su manejo de Internet y las fáciles relaciones con sus paisanos, ejer- ce un fuerte control sobre los que emplea. Los remunera menos que en La Ribera, por cuanto es más bajo el precio de la uva (unos 60 cts. $€$ el kilo, frente a 1 o 1,2 $€ / \mathrm{kg}$ en La Ribera). El viñedo de Rueda, con un auge y una fuerza espectacular, está atrayendo a grandes bodegas, que no necesitan preocuparse por la mano de obra, proporcionada por estas empresas. De hecho, cuando hay mayor demanda el empresario no duda en dar la voz para atraer cuadrillas temporales de búlgaros y rumanos, que son los que sostienen la viticultura en ambas denominaciones (Sánchez y Serra, 2017, pp. 208-209). Parece que el negocio funciona, puesto que el dueño de esa empresa, en tan sólo diez años, ha logrado gestionar 50 obreros de media anual, que llegan a 200 durante la poda en verde. Ha comprado e implantado 80 hectáreas de viñas propias y gestiona casas de acogida, etc.

Un estilo muy diferente es el de DALMADEL, que, con su veintena de máquinas vendimiadoras y una flota de grandes tractores, no sólo realiza toda la vendimia de Rueda, sino que atiende a la renovación de los viñedos y a la transformación de tierras de secano en viñas en una buena parte de las campiñas del sur del Duero. La mecanización se impone y, junto a ella, ascienden imparables la agricultura empresarial y los asalariados -bien fijos en explotaciones consolidadas, o bien temporales, integrados en las empresas de servicios analizadas-, que van desplazando poco a poco a los agricultores de carácter familiar, para convertirlos en empresarios agrarios, con gran peso y valor creciente en la viticultura.

\section{El crecimiento del número de asalariados en el contexto de un modelo expansivo de viticultura y agricultura empresarial}

Es así como las explotaciones agrarias de Castilla y León que emplean más de 1 unidad de trabajo anual de asalariados aportan cerca de la mitad de la PET (Producción Estándar Total) y de las Unidades Ganaderas Totales (UGT), a pesar de que el predominio de la agricultura familiar en esta región sea evidente, pues un $77 \%$ de sus explotaciones carece de asalariados (Tabla 4 ).

En este sentido, tal como planteábamos en el Congreso de la AGE de Valencia en 2019 (Martínez et al., 2019), se puede comprobar que las empresas agrarias crecen en número y tamaño a costa de la explotación familiar. Así, si analizamos la Tabla 5, veremos que en Castilla y León el trabajo asalariado era muy escaso 
TABLA 4

№ DE EXPLOTACIONES AGRARIAS DE CASTILLA Y LEÓN EN 2016 SEGÚN UNIDADES DE TRABAJO ANUAL DE ASALARIADOS

\begin{tabular}{|l|c|c|c|c|c|c|}
\hline $\begin{array}{c}\text { Rangos de UTA } \\
\text { de asalariados }\end{array}$ & $\begin{array}{c}\text { No total de } \\
\text { explotaciones }\end{array}$ & $\begin{array}{c}\text { Superficie } \\
\text { total (ha) }\end{array}$ & UTA totales & $\begin{array}{c}\text { UTA de } \\
\text { asalariados }\end{array}$ & UGT totales & $\begin{array}{c}\text { Producción } \\
\text { Estándar Total (€) }\end{array}$ \\
\hline Sin asalariados & 70.953 & $3.457 .223,7$ & $40.919,0$ & 0,0 & $943.031,6$ & $2.766 .805 .324,0$ \\
\hline$>0-<1$ UTAA & 13.937 & $1.631 .546,4$ & $6.591,1$ & $2.649,6$ & $192.606,0$ & $705.447 .701,1$ \\
\hline $1-<2$ UTAA & 4.236 & $704.281,7$ & $6.583,8$ & $4.893,1$ & $424.648,9$ & $843.594 .231,7$ \\
\hline 2-<4 UTAA & 1.860 & $423.010,7$ & $4.883,4$ & $4.594,8$ & $340.606,7$ & $643.667 .858,1$ \\
\hline 4-<8 UTAA & 870 & $266.001,4$ & $4.345,9$ & $4.260,4$ & $220.282,0$ & $454.404 .759,3$ \\
\hline $8-<16$ UTAA & 183 & $25.149,2$ & $1.903,0$ & $1.893,0$ & $107.116,1$ & $185.057 .885,9$ \\
\hline $16-<32$ UTAA & 23 & $11.348,2$ & 487,3 & 487,3 & $30.996,5$ & $69.672 .578,8$ \\
\hline$>=32$ UTAA & 21 & $7.455,9$ & $2.993,9$ & $2.992,9$ & $39.766,0$ \\
\hline TOTAL >1 UTAA & 7.194 & $1.437 .247,1$ & $21.197,3$ & $19.121,4$ & $1.163 .416,1$ & $\mathbf{2 . 3 0 8 . 1 6 6 . 5 1 3 , 8}$ \\
\hline Total general & $\mathbf{9 2 . 0 8 3}$ & $\mathbf{6 . 5 2 6 . 0 1 7 , 2}$ & $\mathbf{6 8 . 7 0 7 , 3}$ & $\mathbf{2 1 . 7 7 1 , 1}$ & $\mathbf{2 . 2 9 9 . 0 5 3 , 7}$ & $\mathbf{5 . 7 8 0 . 4 1 9 . 5 3 8 , 8}$ \\
\hline
\end{tabular}

Fuente: INE, Encuesta sobre la Estructura de las Explotaciones Agrícolas 2016. Microdatos. Elaboración propia.

dos decenios antes. No llegaba más que al $18 \%$ del empleo total en la Encuesta de 1997 (expresado en UTA), mientras que en la de 2016 casi llegó a duplicarse (32\%). Incluso en aquella fecha muchas explotaciones grandes, gestionadas por "empresarios agrarios", correspondían realmente a un tipo de agricultura familiar más que empresarial, pues en el rango más alto -el de las explotaciones con más de 16 unidades de trabajo anual- apenas había asalariados. Ello indica que eran gestionadas y trabajadas por los miembros de la familia del titular, probablemente con una men- talidad más propia de un terrateniente, con todas sus connotaciones sociales, que de un empresario agrario (Tabla 5).

Evidentemente, este cambio de actitud de los hacendados o terratenientes ha motivado que hoy la explotación agraria se valore más como un bien económico que como un mero factor de prestigio social, tanto en Castilla y León como en el resto España, donde el trabajo asalariado ha adquirido mucho más peso que en Castilla y León. Ello se debe a la contratación de mano de obra externa para labores agríco-

TABLA 5

№ DE EXPLOTACIONES AGRARIAS DE CASTILLA Y LEÓN EN 1997 SEGÚN UNIDADES DE TRABAJO ANUAL DE ASALARIADOS

\begin{tabular}{|l|c|c|c|c|c|c|}
\hline $\begin{array}{c}\text { Rangos de UTA } \\
\text { de asalariados }\end{array}$ & $\begin{array}{c}\text { No total de } \\
\text { explotaciones }\end{array}$ & $\begin{array}{c}\text { Superficie total } \\
\text { (ha) }\end{array}$ & UTA totales & $\begin{array}{c}\text { UTA de } \\
\text { asalariados }\end{array}$ & UGT totales & $\begin{array}{c}\text { Producción } \\
\text { Estándar Total (€) }\end{array}$ \\
\hline Sin asalariados & 89.215 & $2.781 .752,0$ & $67.087,4$ & 0,0 & $994.927,3$ & $1.137 .883 .819,4$ \\
\hline$>0-<1$ UTAA & 21.825 & $2.720 .418,5$ & $15.999,1$ & $2.030,0$ & $170.087,7$ & $341.397 .945,4$ \\
\hline $1-<2$ UTAA & 3.396 & $630.056,4$ & $5.809,0$ & $3.911,3$ & $176.101,0$ & $175.098 .951,4$ \\
\hline $2-<4$ UTAA & 2.301 & $593.887,7$ & $6.195,7$ & $5.857,2$ & $218.002,3$ & $202.344 .697,5$ \\
\hline $4-<8$ UTAA & 631 & $214.188,3$ & $3.196,5$ & $3.099,1$ & $178.306,5$ & $101.546 .885,9$ \\
\hline $8-<16$ UTAA & 131 & $82.870,5$ & $1.306,8$ & $1.285,4$ & $63.863,4$ & $36.228 .581,1$ \\
\hline $16-<32$ UTAA & 31 & $20.402,5$ & 650,5 & 650,5 & $34.364,5$ & $17.362 .218,4$ \\
\hline$>=32$ UTAA & 14 & $28.095,8$ & 841,0 & 840,9 & $43.465,0$ & $18.520 .511,1$ \\
\hline TOTAL >1 UTAA & 6.504 & 1569501,2 & $17.999,3$ & $15.644,4$ & $714.102,7$ & $551.101 .845,5$ \\
\hline Total general & $\mathbf{1 1 7 . 5 4 3}$ & $\mathbf{7 . 0 7 1 . 6 7 2}$ & $\mathbf{1 0 1 . 0 8 5 , 8}$ & $\mathbf{1 7 . 6 7 4 , 4}$ & $\mathbf{1 . 8 7 9 . 1 1 7 , 6}$ & $\mathbf{2 . 0 3 0 . 3 8 3 . 6 1 0 , 4}$ \\
\hline
\end{tabular}

Fuente: INE, Encuesta sobre la Estructura de las Explotaciones Agrícolas 1997. Microdatos. Elaboración propia. 
las intensivas, estacionales o de temporada, principalmente en la horticultura, en la fruticultura, en parte de la olivicultura y, con tendencia creciente, en la viticultura. Ésta ha sido la clave, como hemos visto, del crecimiento de las empresas de servicios agrarios. Pero, además de esta mano de obra temporal, han crecido extraordinariamente los asalariados fijos.

Si se observan los mapas (Figuras 4 y 5), se aprecia una alta coincidencia de la mano de obra asalariada de cada municipio con la situación de su término en comarcas de OTE dominante intensiva. Para contextualizar el fenómeno en Castilla y León, se aporta el mapa de España (OTE comarcal y asalariados por municipio), que pone de manifiesto una distribución de asalariados determinada por los cuatro aprovechamientos citados (hortícolas, frutícolas, olivícolas y vitícolas). De entrada, podemos ver que el empleo agrario asalariado se concentra en las áreas de invernaderos de Almería, Murcia, Alicante y, secundariamente, en otros espacios intensivos sin invernaderos. Por otro lado, este mapa concuerda claramente con la distribución de los cotizantes a la Seguridad Social por la rama agraria. Igualmente, destaca el peso del olivar en Andalucía, que siempre tuvo una alta capacidad de empleo y lo ha incrementado por el apoyo recibido de la PAC. Asimismo, sobresalen las explotaciones de la fruticultura del Cinca-Segre-Ebro, especialmente en la Llitera-Segriá, a las que secundan las de las Vegas Bajas del Guadiana o las vitícolas de la Rioja y, a más distancia, las huertas del norte de Segovia-sur de Valladolid; a todas ellas se suma el empleo en la ganadería industrial sin tierra, de porcino y aviar, que también se distribuye con cierta regularidad por el interior de Galicia. También puede tener incidencia la expansión de la agricultura a tiempo parcial, que, como ya apuntaba Langreo (2002), permite mantener el control de la explotación, pero con trabajo aportado por asalariados o por empresas de servicios.

Este marco de las explotaciones y empresas agrarias de España pone de manifiesto la progresiva re-

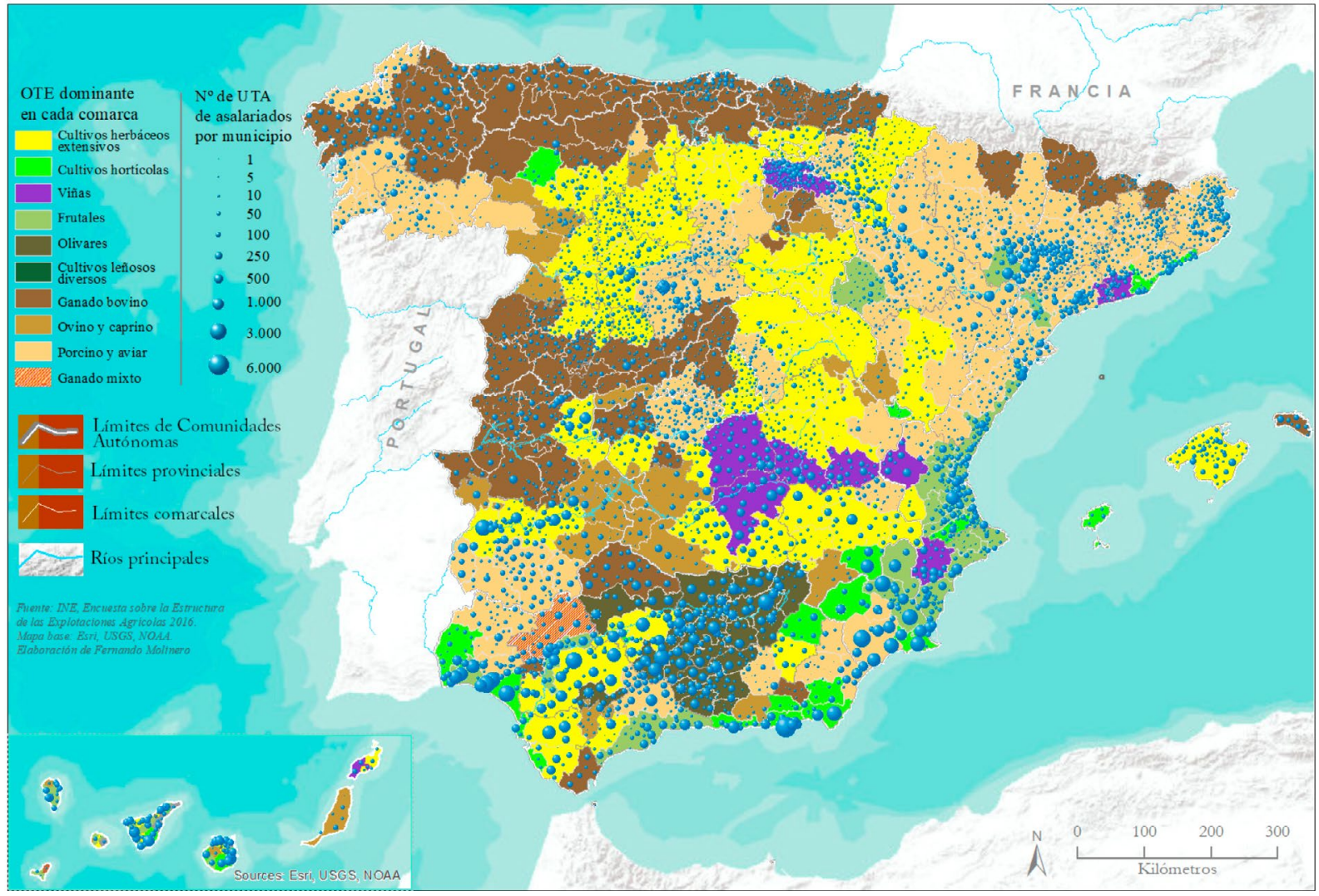

Fuente: INE, Encuesta sobre la Estructura de las Explotaciones Agrícolas, 2016. Elaboración propia. 
ducción del número de explotaciones, que cada vez se hacen más grandes, mejor gestionadas y con una capacidad de empleo muy superior a la de la agricultura dedicada a los secanos extensivos. En el caso de Castilla y León, se organizan en forma de explotaciones familiares, a menudo conformadas como auténticas empresas, pero sin apenas empleo asalariado, en contra de lo que se observa en las comarcas de aprovechamientos intensivos, donde una buena parte del empleo por cuenta ajena corresponde a inmigrantes llegados al campo antes de la crisis.

Siguiendo a Alario (2019), la dispersión espacial es la norma entre los inmigrantes marroquíes, dada su vinculación laboral mayoritaria con las actividades agrarias. Tanto la población de origen marroquí como búlgaro muestran una notable dispersión territorial y mayor presencia en espacios de personalidad agraria nítida, como la Tierra de Campos vallisoletana o palentina, o como las Ilanuras leonesas, donde la espe- cialización agraria (agrícola y ganadera) constituye una interesante, aunque no generalizada, opción laboral. En algunos casos, se dan concentraciones singulares, como ocurre con los búlgaros en la Tierra de Campos vallisoletana, donde suponen el $80 \%$ de los residentes extranjeros. Están mayoritariamente concentrados en un municipio, Mayorga de Campos, en el que residen tres cuartas partes de los búlgaros de la comarca. Por su parte, los rumanos comparten algunas de estas características espaciales, aunque con una menor dispersión y mayor concentración en los espacios preferentes del sur de Castilla y León, en los agroindustriales intensivos del Carracillo segoviano y en la Tierra de Pinares vallisoletana, con una importante presencia también en la Ribera del Duero.

El mapa (Figura 5) recoge la distribución municipal de los asalariados agrarios en Castilla y León. Aunque no refleja el país de origen, sí manifiesta una distribución relativamente regular, con un cierto predomi-

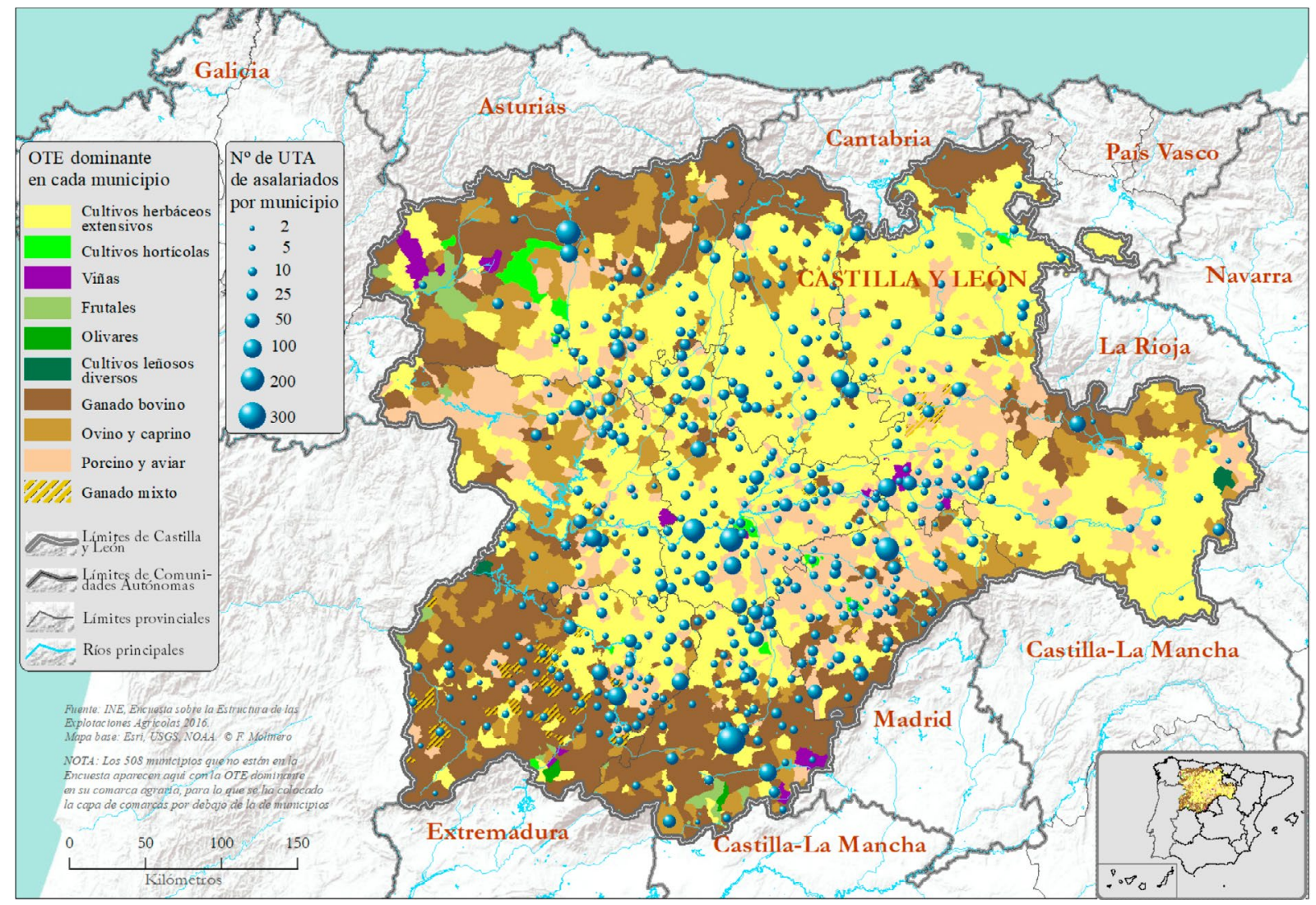

Fuente: INE, Encuesta sobre la Estructura de las Explotaciones Agrícolas, 2016. Elaboración propia. 
nio en el valle del Duero y en las comarcas de horticultura intensiva, además de en las de ganadería industrial. Los aprovechamientos ganaderos muestran una escasa capacidad de empleo asalariado (Martínez et al., 2019), pues hay muy poco en los bordes montañosos y en las penillanuras del oeste, por más que en Salamanca se observe una cierta proliferación. Son las llanuras agrícolas las tierras que concentran la mayor parte de ese tipo de empleo, con una distribución más o menos regular, aunque con más peso en las comarcas de regadío de León, en las vegas y terrazas del Duero y en las campiñas meridionales durienses en las que se integra la explotación hortícola (noroeste de Segovia y sur de Valladolid) con la explotación intensiva de porcino y con la viticultura. En sentido contrario, se ve un cierto vacío en las grandes áreas de agricultura general, dedicada a cultivos herbáceos extensivos, principalmente en las plataformas sorianas, en los altos páramos del norte de Burgos, en los Cerratos, en Boedo-Ojeda palentinos y en algunos otros piedemontes montañosos de León. Resulta llamativo que la fruticultura del Bierzo, que aparece como OTE dominante en varios municipios, no sea capaz de generar empleo asalariado, al tratarse de pequeñas explotaciones familiares, a menudo gestionadas a tiempo parcial.

\section{DISCUSIÓN DE RESULTADOS}

Los procesos de salarización de las explotaciones y de externalización de los servicios agrarios se están generalizando en toda Europa, como bien destacan los autores del reciente informe del Parlamento Europeo sobre la situación y perspectivas del empleo agrario en la UE. La UE-27 en conjunto ha pasado de 13,1 millones de UTA en 2003 a 9,5 en 2018, con una pérdida del $30 \%$ de las UTA, lo que ha dado lugar a una reducción pareja del número de explotaciones pequeñas y medianas, mientras ha aumentado el de las mayores de 100 ha, por más que en algunos Estados miembros (EM) haya crecido la fuerza de trabajo y el número de explotaciones (República Checa, Grecia, Eslovenia...). Asimismo, añade el informe que mientras en algunos EM y regiones se ha consolidado la explotación familiar, como en Irlanda, Baviera, Norte de Italia, Austria, norte de Portugal..., en otras predomina el trabajo externo asalariado, como en el sur de Alemania occidental, la mayor parte de Francia o el sur de España (Schuh, B et al., 2019, p. 9). Nosotros añadiríamos aquí que el alquiler de la mano de obra no sólo se extiende por determinadas regio- nes en las que predomina la empresa agraria, sino que lo hace por todas las regiones, o comarcas, en las que predominan los aprovechamientos intensivos, entre los que se encuentra el viñedo. Lo hemos comentado para el viñedo de La Rioja y creemos haberlo demostrado para el caso de La Ribera del Duero y Rueda. Es más, el informe destaca como uno de los principales resultados que, "por lo que se refiere al trabajo temporal, no es una práctica exclusiva de la agricultura mediterránea, sino que se extiende por toda Europa, incluida Flandes, los Países Bajos y Alemania occidental" (Schuh, B et al., 2019, p. 9).

Pero la externalización del trabajo agrario y el auge de las empresas de servicios en la agricultura vienen de lejos. Ya lo planteaba el profesor Arnalte (2003) en el Libro Blanco del Desarrollo Rural y lo hacía también Langreo (2002, p. 45), cuando iba más allá y hablaba incluso de la externalización de la gestión. Ella lo atribuía especialmente a la creciente mecanización y tecnificación, que permitía la creación de empresas especializadas y muy tecnificadas para determinadas labores o para cubrir la demanda de agricultores a tiempo parcial, o jubilados o de otros colectivos incapaces de hacer frente por sí mismos a las exigencias de un mercado cada vez más competitivo. Más tarde, la propia Langreo, a través de la Sociedad de Estudios Saborá, publicaba un informe realizado para el MAPA (Saborá, 2006, p. 188) sobre las empresas de servicios de maquinaria agrícola, en el que insistía en la necesidad de reconocer la magnitud de la externalización de tareas mecanizadas. La externalización es un fenómeno de progresiva importancia, como lo demuestra, asimismo, el reciente trabajo de Pereira (2019) sobre el valor creciente de los profesionales agrarios que prescinden de mano de obra en la ganadería gallega para contratar los servicios de empresas innovadoras que les permiten adaptarse a un mercado cada vez más competitivo.

En efecto, muchas empresas de servicios agrícolas asumen labores de decisión, de gestión y de cobertura de todo tipo de trabajos, pero este no es el caso de las explotaciones vitícolas del Duero. Aquí, se trata, más bien, de poner en marcha la reconversión varietal, concentrada en unas épocas del año, o bien de labores culturales anuales. Este tipo de empresas ha continuado aumentando, innovando y ofreciendo cada vez más servicios, al estilo de lo que hemos analizado para DALMADEL $u$ otras en Rueda.

No obstante, nuestro objetivo aquí no es el estudio de todas las empresas que ofrecen servicios a la agricultura, que según SABI serían 5.145 en España (en 
enero de 2020), sino tan sólo de las que ofrecen servicios vitícolas. Así, persiguiendo la innovación, que no cesa, una pequeña empresa de Arroyo de la Encomienda (Valladolid, que ni siquiera aparece en la Base SABI) ofrece todo tipo de servicios ambientales para la viticultura, controlando con drones el estado fenológico de las plantas, la temperatura del aire, la humedad del suelo, las necesidades o carencias de nutrientes y otra serie de parámetros cuya descripción envía a los viticultores clientes por medio de sus teléfonos móviles, para que actúen en consecuencia.

En este contexto, cabe citar los trabajos que realizan desde el Departamento de Sociología y Antropología Social de la Universidad de Valencia, en colaboración con el Instituto de Investigaciones Sociales de la Universidad Nacional Autónoma de México. En uno de ellos se relaciona precisamente el trabajo externalizado en la agricultura con la mano de obra inmigrante, para el caso de La Ribera del Duero; analizan la entidad de los inmigrantes en algunos de sus municipios y correlacionan la tasa de inmigrantes con la extensión y el valor del viñedo y las bodegas. Así, destacan los casos de los municipios burgaleses de Anguix (26,3\% de población inmigrante en 2012), Roa (17,3\%), Aranda de Duero (11,6\%) o el vallisoletano Peñafiel (13,1\%), entre otros (Sánchez y Serra, 2013, p. 105). Aunque el número de inmigrantes haya caído en los años posteriores a los que analizan, por la dureza de la Gran Recesión, ha vuelto a crecer su importancia en el último trienio, tanto más cuanto que los propios empleadores están buscando alojamiento digno para los inmigrantes en los pueblos, con el fin de mantener su presencia en ellos y disponer de su fuerza de trabajo. Ahora bien, como ya indicaba Alario (en Martínez et al., 2019, pp. 774-775), el comportamiento de los inmigrantes rurales concuerda con el de los nacionales: cuando las condiciones de trabajo o de vivienda son inadecuadas, o los salarios parcos, acaban emigrando a la ciudad o cambiando de sector, dejando el agrario por el de la construcción - la hostelería, o como empleadas de hogar en el caso de las mujeres, u otros.

Este mismo grupo acaba de publicar los resultados de un proyecto sobre reestructuración vitivinícola, mercados de trabajo y trabajadores inmigrantes en el que se compara la situación en Estados Unidos, España y Portugal. Aparte de las consideraciones realizadas sobre la Ribera del Duero (Sánchez, 2019), tiene interés destacar el análisis de Gadea y Torres (2019, p. 196-198) sobre la contratación de inmigrantes para las labores vitivinícolas en los viñedos de
Utiel-Requena (Valencia). Estos autores constatan el fuerte crecimiento de los contratos vitícolas entre 2007 y 2014, basándose en los datos del Servicio de Empleo y Formación de la Comunidad Valenciana. Comentan que aproximadamente un $50 \%$ de los obreros son inmigrantes provenientes principalmente de Rumanía y Bulgaria, aunque algo más de la mitad siguen siendo españoles. Añaden que casi todos son varones y que sólo en la vendimia las mujeres alcanzan una proporción significativa (un $20 \%$ de los inmigrantes). Comentan, además, que en un principio -a finales de los años 1990- no eran dados de alta en la Seguridad Social. Ante las campañas de la Inspección de Trabajo, los sindicatos agrarios, como el de Agricultores Solidarios, lograron realizar contratos en origen desde 2004, además de recurrir a inmigrantes residentes en otros municipios y ciudades valencianas, con lo que a veces acudían familias enteras, sin discriminación de sexo ni de edad. Merced a la gestión sindical se seleccionaban los trabajadores en origen, se facilitaban los trámites, se realizaba la asignación de trabajadores a los empresarios, se gestionaba su alojamiento y todo lo referente a contratos y pagos a Seguridad Social (Gadea y Torres, 2019, pp. 199-200). En definitiva, los sindicatos asumían el papel que hoy ejercen las SLU.

En ese mismo proyecto de investigación, Sánchez estudia el empleo de abundante mano de obra en la viticultura del Valle de Napa (California, EEUU). En esa comarca de renombre mundial se firmaban (en 2012) unos diez mil contratos de trabajo para cuidar de una superficie vitícola un poco inferior a la de La Ribera del Duero, de los que un $27 \%$ correspondía a inmigrantes y la mayoría de ellos trabajaba menos de 150 jornadas al año. Más del $80 \%$ de los inmigrantes eran mejicanos que entraron en el país durante las tres últimas décadas del siglo pasado, mientras que ahora disminuyen nítidamente los flujos migratorios y algunos trabajadores mejicanos son reemplazados por otros centroamericanos (Sánchez, 2019, pp. 224-227). Es una situación dura, aunque el alojamiento suele estar cubierto por las autoridades del condado o del Estado, incluso con el apoyo de algunos viticultores. ${ }^{10}$

Para el caso europeo, un reciente estudio del Grupo de Empleadores de las Organizaciones Profesionales Agrarias (GEOPA-COPA) (Baiocco, Busse, Cirule, Di Salvo y Lenaerts, 2019) decía que sería un error llegar a la conclusión de que el sector agrario está perdiendo importancia como fuente de empleo en general. La reducción del empleo agrario se debe casi exclu- 
sivamente a los agricultores titulares de las explotaciones y a las ayudas familiares, mientras que los asalariados se han mantenido casi constantes desde 2000. En el informe se atribuye el fenómeno al hecho de que los productores agrarios más pequeños, que a menudo están integrados en una explotación familiar, acaban abandonando el sector o son absorbidos por grandes productores que utilizan más maquinaria que mano de obra para incrementar la productividad del trabajo. Pero, en conjunto en la UE, y especialmente en algunos países, el sector agrario continúa siendo la principal fuente de empleo (Baiocco et al., 2019, p. 10).

\section{CONCLUSIÓN: NUEVA VITICULTURA Y NUEVOS PAISAJES, ENTRE EL APROVECHAMIENTO DE LA MANO DE OBRA INMIGRANTE, LA MECANIZACIÓN Y LA EMPRESARIALIZACIÓN DE LA AGRICULTURA}

La inexorable modernización y tecnificación de la agricultura conduce hacia una disminución constante del número de explotaciones y de agricultores titulares, acompañada de un aumento del tamaño de las unidades de explotación y del empleo asalariado. Los aprovechamientos intensivos continúan demandando abundante mano de obra, que no se puede sustituir por trabajo mecanizado. En las regiones y comarcas de España, así como en Castilla y León, existe una destacable demanda de empleo agrario, cubierta normalmente con mano de obra inmigrante, que es gestionada por empresas de servicios agrarios, muchas de ellas con forma de SLU, que adquieren una entidad creciente y que mueven a decenas de miles de operarios. En una escala más modesta, pero creciente, la viticultura del Duero emplea a una porción significativa de esta mano de obra inmigrante, muy poco consolidada, fácilmente moldeable y sustituible según demanda, dado el contexto de flexibilidad laboral imperante.

Esta nueva viticultura intensiva ha generado una homogeneización paisajística incuestionable, que deriva del predominio absoluto del viñedo en espaldera, con densidades de 2500 a 3500 cepas/ha, con muchos cuidados. Ello configura un campo más ocupado, vivo, exigente $y$, en gran medida, atendido por esa mano de obra inmigrante que, en cuanto puede, deja el campo para marcharse a la "construcción" o a la ciudad, señal de la precariedad laboral del sistema. Como resultado final, se puede decir que conviven dos categorías de explotaciones vitícolas: las de las grandes empresas, con superficies que superan las 200 o 300 ha y producciones de más de 1 millón de botellas/año, por un lado, y las explotaciones familiares, entre 20 y 60 ha (a veces un poco más), en las que todavía domina la mano de obra familiar. En estas últimas, con producciones inferiores a las 300.000 botellas, hay hueco para muchos tipos de negocios, especialmente en los que se dedican a la cría de vinos tintos, pues los que producen blancos se orientan a la empresa tecnificada. En unas y otras, la parte sustancial del trabajo procede de inmigrantes, escasamente remunerados, en condiciones laborales precarias y duras. Ello los empuja hacia otros nichos laborales, en tanto no encuentren albergue y alojamientos dignos que, en parte, ya están siendo atendidos por los empleadores. Aunque la mecanización reduce labores, el viñedo exige un mínimo de 20 jornadas/ha/año, lo que continuará demandando abundante mano de obra, que ya se ha hecho fija en algunos pueblos vitícolas del Duero. Son esos inmigrantes que aportan su trabajo los únicos que están dinamizado el medio rural de esta región en declive demográfico.

\section{RECONOCIMIENTOS}

Esta aportación se inscribe en el Proyecto de Investigación I+D CSO2016-79756-P (AEI/FEDER, UE). Ministerio de Economía, Industria y Competitividad, Programa Estatal de Fomento de la Investigación Científica y Técnica de Excelencia, Subprograma Estatal de Generación de Conocimiento, convocatoria 2016. Asimismo, se inscribe en el Proyecto $I+D+i$ CSO2015-67525-R del MINECO, convocatoria de junio de 2015. 


\section{NOTAS}

1 Aquí llegó muy tarde, e incluso no afectó a determinados pagos de suelos arenosos o cascajosos, poco propicios para el insecto.

2 Niharra sobresale por ser una empresa singular y Gardisancho, por estar dedicada a la siembra de plantón de fresa, frambuesas y arándanos. Los casos de Segovia capital, junto con el de la ciudad de Palencia, se orientan a servicios ganaderos. En Segovia tiene su sede Desarrollos Porcinos de Castilla y León SL (DEPORCYL), orientada hacia la consecución de carnes selectas; en Palencia se encuentra el Laboratorio Interprofesional Lácteo de Castilla y León. El caso de Benavente representa la suma de varias empresas pequeñas, que agrupan bastantes empleados, pero que se dedican a todo tipo de servicios agrícolas y ganaderos; se incluyen, entre ellos, algunos de la magna cooperativa TEO (Tera-Esla-Órbigo).

3 Estos Planes de Reestructuración y Reconversión del Viñedo en la Comunidad de Castilla y León son convocados por la Orden de 9 de abril de 2001 de la Consejería de Agricultura y Ganadería. (BOCyL 73 de 11 de abril).

4 En la nueva organización común del mercado vitivinícola se modifica el potencial de producción, desarrollado en el reglamento (CE) 1227/2000 de la Comisión de 31 de mayo de 2000, por el que se fijan las disposiciones de aplicación, reguladas posteriormente por el Real Decreto 1472/2000 de 4 de agosto. La propia Consejería de Agricultura ya disponía de una Orden de 6 de octubre de 2000 por la que se regulaban los planes de reestructuración y reconversión. De esta manera, nacen, amparados por el FEOGA (Fondo Europeo de Orientación y Garantía Agraria), toda una regulación de ayudas que, en nuestro caso, la Consejería de Agricultura y Ganadería de la Junta de Castilla y León regulará en campañas sucesivas. En ellas

\section{REFERENCIAS BIBLIOGRÁFICAS Y FUENTES}

Agronegocios (2017). Menos explotaciones agrícolas, pero sube hasta 25,06 ha la SAU media entre 2013 y 2016. Agronegocios sección "Nacional", 15 de diciembre. Recuperado de https://www. agronegocios.es/menos-explotaciones-agricolassube-2506-ha-la-sau-media-2013-2016/ [Consultado 03/junio/2019]. primarán los planes colectivos, entre los que, dentro de la DO Rueda, sobresalen los llevados a cabo por la cooperativa Agrícola Castellana (La Seca, Valladolid) y que agruparán a la mayor parte de los solicitantes del espacio que estudiamos. (BOCyL 73, miércoles 11 de abril de 2001, p. 6014, http://bocyl.jcyl.es/boletines/2001/04/11/pdf/ BOCYL-D-11042001-3.pdf) (Consultado 16/ noviembre/2013).

5 FEGA, 2019: https://www.fega.es/es/PwfGcp/es/ regulacion_mercados/restvi/index.jsp

6 Miguel Esteban de Íscar es socio fundador de la bodega Diez Siglos de Verdejo. Además de realizar su tesis doctoral sobre los viñedos de Rueda y la Tierra de Medina del Campo, conoce con precisión su dinámica.

7 Recuperado por Esteban de Íscar de: https://www. paginasamarillas.es/f/serrada/vod-vinegarden_ 221022486_000000002.html

8 Trabaja con dos socios franceses: el actor Gerard Depardieu y el bodeguero y comerciante de vinos de alto nivel Bernard Magrez, un nombre que goza de reconocimiento internacional dentro del sector. VOCARRAJE supervisa y cuida las cinco hectáreas de viñedo que estos dos socios franceses han adquirido en esta localidad, de cuyas viñas viejas salen los prestigiosos caldos que elabora en la DO Toro Domaine Magrez Espagne, que produce también vino en el Priorat.

9 https://www.facebook.com/pg/VINOABDONSEGO VIA/about/?ref=page_internal (Consultado 30/11/ 2019).

10 La autora pone como ejemplo el centro de farmworkers de Mondavi, que funciona como alojamiento durante el programa bracero. Esos centros dependen actualmente del California Human Development Corporation (Sánchez, 2019, p. 232).

Agronews Castilla y León (2019). UCCL exige un comunicado oficial al Consejo Regulador de Rueda sobre la decisión de restringir y limitar las plantaciones de viñedo. Agronews Castilla y León. Recuperado de https://www.agronewscastillay leon.com/uccl-exige-un-comunicado-oficial-al- 
consejo-regulador-de-rueda-sobre-la-decisionde-restringir-y [Consultado 29/diciembre/2019].

Alario, M. (2019). Crisis e inmigración en el medio rural de Castilla y León: Escenarios socio-territoriales para el arraigo de los inmigrantes y la sostenibilidad social de las áreas rurales (CSO2015-67525-R), financiado por el MINECO en el marco del Programa Estatal de I+D+i orientado a los Retos de la Sociedad (convocatoria 17/06/2015). Informe inédito.

Arnalte, E. (2003). Las Estructuras Agrarias. 3. Los Regímenes de Tenencia de la Tierra y el Cambio Estructural; 3. Otras formas de cesión de la tierra: vías alternativas de cambio estructural. En MAPA, Libro Blanco de la Agricultura y el Desarrollo Rural (pp. 77-88). Madrid, España: Ministerio de Agricultura, Secretaría General Técnica.

Baiocco, S., Busse, M., Cirule, E., Di Salvo, M. y Lenaerts, K. (2019). Los costes de la mano de obra en el sector agrícola: estudio comparativo. GEOPA-COPA. Recuperado de https://copa-cogeca. e u/img/user/files/COPA-GEOPA/Final report2019/EA(19)8551ES\%5B1\%5D.pdf

Eurostat (2015). Farm structure statistics. Statistics Explained. Estadísticas sobre estructura de las explotaciones agrarias. Recuperado de https:// ec.europa.eu/eurostat/statistics-explained/index. php?title=Agriculture,_forestry_and_fishery_ statistics

Eurostat (2018): Farms and farmland in the European Union-statistics. Statistics Explained. Estadísticas sobre estructura de las explotaciones agrarias. Recuperado de https://ec.europa.eu/eurostat/ statistics-explained/index.php?title= Agriculture,_forestry_and_fishery_statistics

Esteban de Íscar, M. (2015). Evolución histórica y transformaciones recientes de la agricultura en Tierra de Medina. La especialización vitícola en la denominación de origen Rueda. Serrada como ejemplo. (Tesis Doctoral). Universidad de Valladolid, Valladolid. Cfr. especialmente Cap. XI, pp. 9881091, sobre transformación de la vitivinicultura.

FEGA (2019). https://www.fega.es/es/PwfGcp/es/ regulacion_mercados/restvi/index.jsp [Consultado 30/diciembre/2019].

Gadea, M. E. y Torres, F. J. (2019). Reestructuración vitivinícola, cambios en la organización del trabajo y mano de obra inmigrante en Utiel-Requena (España). En Sánchez, M. J. et al. (coords.), Rees- tructuración vitivinícola, mercados de trabajo y trabajadores inmigrantes (pp. 179-206). México: UNAM. Recuperado de http://ru.iis.sociales. unam.mx/jspui/bitstream/IIS/5693/2/reestruc tiuracion_vitivinicola.pdf

Gallego, J. R. (2010). La agricultura a tiempo parcial y la externalización de servicios agrarios como vehículo del cambio estructural. Revista Española de Estudios Agrosociales y Pesqueros, 225, 13-45. doi: https://doi.org/10.22004/ag.econ.178682.

Huetz de Lemps, A. (1967, 2005). Vinos y viñedos de Castilla y León. Valladolid, España: Fundación Castellanoleonesa para la cultura del vino, Junta de Castilla y León, Consejería de Agricultura y Ganadería. Extraído de la obra original Vignobles et vins du nord-ouest de l'Espagne. Bordeaux, Francia: Bellenef.

INE (1997 y 2016). Encuesta sobre la Estructura de las Explotaciones Agrícolas 1997. Ídem 2016. Microdatos, por CCAA. Recuperado de INEbase: http://www.ine.es/dyngs/INEbase/es/operacion. htm?c=Estadistica_C\&cid $=1254736176854 \&$ men $u=$ resultados \& secc $=1254736194991 \& i$ $d p=1254735727106$

INE (2015). Encuesta sobre la Estructura de las Explotaciones Agrícolas 2016, Proyecto. Recuperado de http://www.ine.es/daco/daco42/agricultura/ meto_2016.pdf

INE (2019). Notas de prensa. Recuperado de http:// www.ine.es/prensa/eeea_2016.pdf

INSS (2019). Tesorería General de la Seguridad Social, Cuentas y trabajadores inscritos por régimen, municipio y actividad, clasificación CNAE 2009 a dos dígitos, en junio de 2018. Base de datos de acceso restringido, obtenida en el Portal de la Transparencia (https://sede.transparencia.gob. es/).

Langreo. A. (2002). La externalización del trabajo agrario y las empresas de servicios a la agricultura. Economía Agraria y Recursos Naturales, 2(1), 45-67.

Lourenço-Gomes, L; Pinto L.M.C. y Rebelo, J. (2015). Wine and cultural heritage. The experience of the Alto Douro Wine Region. Wine Economics and Policy, 4(2), 78-87. doi: https://doi.org/10.1016/j. wep.2015.09.001

MAPA (2019). Informe DOP españolas, Campaña 2017/18. Madrid, España: Subdirección General 
de Calidad Diferenciada y Producción Ecológica. Recuperado de https://www.oemv.es/informedop-espanolas-campana-2017-18

Martínez, M.; Herrero, D.; Baraja, E.; Alario, M y Molinero, F. (2019). La emergencia de nuevos modelos productivos agrarios y laborales en espacios rurales en declive demográfico. El caso de Castilla y León en el contexto de España. En Actas del XXVI Congreso de la AGE (pp. 762-777). Valencia, España: AGE-Universitat de València. Recuperado en https://www.age-geografia.es/site/wpcontent/uploads/2020/01/Actas-CongresoConclusiones-AGE-VLC2019_compressed_ reduce-1.pdf

Molinero, F. (1979). La Tierra de Roa, la crisis de una comarca vitícola tradicional. Valladolid, España: Dpto de Geografía, Universidad de Valladolid.

Molinero, F. y Martínez, M. (2018). Productivismo y paisaje: las empresas de servicios en los espacios vitivinícolas del Duero. En Actas del Congreso Iberoamericano de Estudios Rurales XII CIER, (pp. 430-433). Segovia, España: Asociación Española de Economía Agraria.

Peña, M. (1987). Tierra de Campos. La integración de un espacio rural en la economía capitalista. Valladolid, España: Universidad de Valladolid, Caja de Ahorros y Monte de Piedad de Salamanca.

Pereira, Á (2019). Os servizos no cambio de modelo agrario: Especialización, asociacionismo e cooperativismo. Pontevedra, España: Laiovento.

Ponte, S. y Ewert, J. (2009). Which Way is "Up" in Upgrading? Trajectories of Change in the Value Chain for South African Wine. World Development, 37, 1637-1650. doi: https://doi. org/:10.1016/j.worlddev.2009.03.008

Registro Mercantil Central (RMC) (2019). Estadística Año 2018. Recuperado de http://www.rmc.es/ documentacion/publico/Estadisticas/ ESTADISTICAS-2018.pdf [Consultado 03/junio/ 2019].

Saborá (2006). Estudio para la caracterización de las empresas de servicios de maquinaria agrícola. Realizado por Saborá para el Ministerio de Agricultura, Pesca y Alimentación. Recuperado de https://www.mapa.gob.es/es/agricultura/ publicaciones/empresas_tcm30-57886.pdf [Consultado 15/06/2020]

Sánchez, M. J. y Serra, I. (2013). Trabajo inmigrante y actividad vitivinícola: el Caso de la Ribera del Duero. methaodos.revista de ciencias sociales, 1(1), 96-113. doi: https://doi.org/10.17502/m. rcs.v1i1.27

Sánchez, M. J. y Serra, I. (2017). Migración y reemplazo étnico en la viticultura: Rumanos y búlgaros en Ribera del Duero, España. Migraciones Internacionales, 9 (2), pp. 201-225. doi: https://doi. org/10.17428/rmi.v9i33.339

Sánchez, M. J. (2019). Las transformaciones en la viticultura en el condado de Napa, California y su impacto en el mercado de trabajo agrícola. En Sánchez, M. J. et al. (Coords.), Reestructuración vitivinícola, mercados de trabajo y trabajadores inmigrantes (pp. 209-247). México: UNAM, IIS, Colef y Conacyt. Recuperado de http://ru.iis. sociales.unam.mx/bitstream/IIS/5693/2/ reestructiuracion_vitivinicola.pdf [Consultado 03/junio/2019].

Sánchez, M. J.; Torres, F.; Serra, I. y Gadea, M. E. (coords.) (2019): Reestructuración vitivinícola, mercados de trabajo y trabajadores inmigrantes. México: UNAM, IIS, Colef y CONACYT.

Schuh,B et al. (2019): EU farming employment: current challenges and future prospects, European Parliament, Policy Department for Structural and Cohesion Policies, Brussels.

UE (2019). Reglamento (UE) no 1308/2013 del Parlamento Europeo y del Consejo, de 17 de diciembre de 2013, por el que se crea la organización común de mercados de los productos agrarios y por el que se derogan los Reglamentos (CEE) no 922/72, (CEE) no 234/79, (CE) no1037/2001 y (CE) no $1234 / 2007$.

UE (2019): Programa "Copernicus" de observación de la Tierra, CLC 2018. Recuperado de https://land. copernicus.eu/pan-european/corine-land-cover [Consultado 03/junio/ 2019].

Vinegarden (2019). Recuperado de https://www. paginasamarillas.es/f/serrada/vod-vinegarden_ 221022486_000000002.html [Consultado 23/ diciembre/2019]. 